Año L. urtea

$125-2018$

Urtarrila-ekaina

Enero-junio

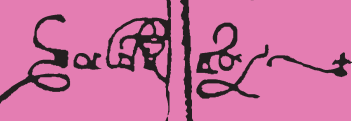

(4)

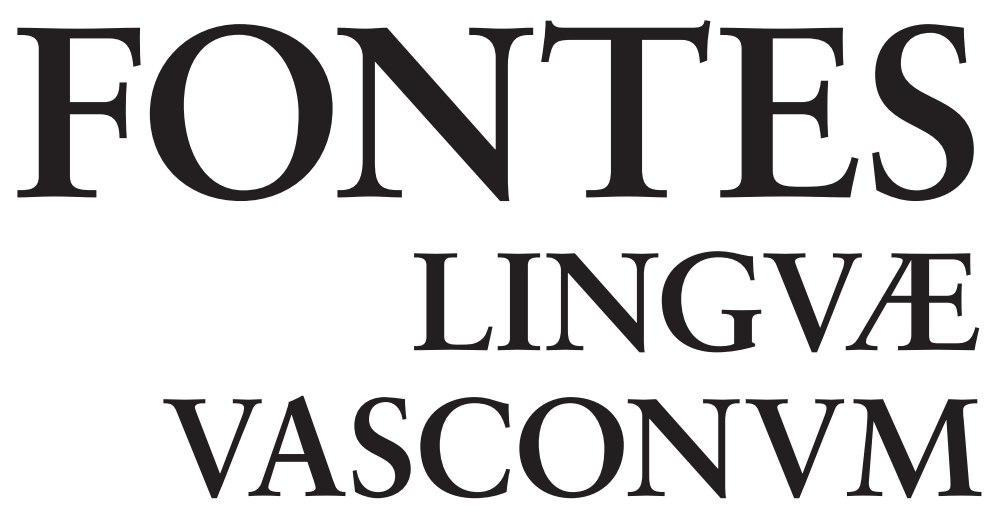

STVDIA ET DOCVMENTA

SEPARATA

\section{Erroibarko aldaeraren}

\section{inguruan}

(eta 6 - Esteribarko erdialdeko azpialdaera.

Bigarren erdia)

Koldo Artola

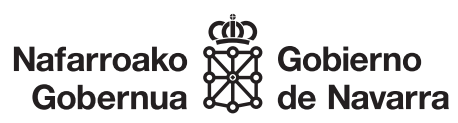

0000 


\section{Erroibarko aldaeraren inguruan}

\section{(eta 6 - Esteribarko erdialdeko azpialdaera. Bigarren erdia)}

Acerca de la variedad de Erro (y 6 - Subvariedad del centro de Esteribar. Segunda mitad)

A look at the Erro variety (and 6 - Sub-variety of the Esteribar centre. Second half)

Koldo ARTOLA

Donostiako Aranzadi Zientzi Elkarteko Etnografi Sailekoa

kmartola@gmail.com

Esker biziak damazkiot lana irakurri eta zenbait iradokizun egin didan Xabier semeari, Euskal Filologian lizentziaduna denari. 


\section{LABURPENA}

Honen bidez bukatutzat emango dugu Louis-Lucien Bonaparte euskalariak Erro izenekotzat jo zuen aldaerari eskaini diogun sei saiotako lana. Aldaera hau printzeak cispamplones azpieuskalkiaren barruan sartu zuen, Hegoaldeko goi-nafarrera deitu euskalkiaren baitan, betiere, eta Erroibarko mintzamoldeek zein Esteribarko gehienek elikatzen dute, azken ibar honetako batzuk Bonapartek, sailkapen kontu hauetarako, ibar honetatik bereizi eta Artze deitu zuen aldaeraren baitan kokatu zituenez.

Gako hitzak: Hego-nafarrera; Erroibarko aldaera (Esteribarko erdialdeko azpialdaera); euskal dialektologia.

\section{RESUMEN}

Con la presente entrega finalizamos el trabajo dedicado a la variedad vasca que el príncipe Bonaparte denominó de Erro, incluida por él dentro del subdialecto cispamplonés e integrado éste, a su vez, en el dialecto Alto-navarro meridional. Esta variedad, según Bonaparte, se nutría de las hablas de los valles de Erro y Esteribar, exceptuadas las de algunos pueblos y aldeas del sur de este último valle, que integró en la variedad de Arce.

Palabras clave: Euskera navarro meridional; variedad de Erro (subvariedad del centro de Esteribar); dialectología vasca.

\section{ABSTRACT}

This instalment brings to a close this study of the variety of the Basque language which Bonaparte referred to as the Erro variety and included in the cispamplonés subdialect, in turn part of the Southern Upper Navarrese dialect. According to Bonaparte, this variety drew from the forms of the language spoken in the Valley of Erro and Esteribar, bar those used in a few villages and hamlets in the south of the latter, which he included in the Arce variety.

Keywords: Southern Navarrese Basque; Erro variety (sub-variety of the Esteribar centre); Basque dialectology. 
1. Azken sarreratxoa. 2. Hizkera honen eZaugarriez bi hitz. 3. Datuen TRANSKRIPZIOEZ BESTE BI. 4. SAIO HONETAKO BERRIEMAILEEN ZERRENDA 5. INBULUZKeTA. 5.1. Apolinaria Egozkue Goñi. 6. UrdaitZ. 6.1. Fermina Zuazu Urdaniz. 7. EzKIROTZ. 7.1. Domingo Bizkai Santesteban. 8. OsTERITZ. 8.1. Josefa Santesteban Lizoain. 9. ZAI. 9.1. Celedonia Bizkai Santesteban. 10. ERREA. 10.1. Martin Esain Eugi. 10.2. Josefa Esain Eugi 10.3. Maria Etxeberria Erro. 11. BibliogRAFIA.

\section{AZKEN SARRERATXOA}

Louis-Lucien Bonaparte printzearen 1863ko mapa gogoan, alde batetik, eta haren jarraitzaile Pedro de Yrizarrek, hartan oinarriturik, zedarritu zituen azpialdaerak ere kontuan izanda, bestetik, «Erroibarko aldaeraren inguruan» izenburu orokorra eman diogun lanaren azken saioa dakargu orain lerro hauetara, Esteribarren erdialdean-edo kokatu Inbuluzketa, Urdaitz, Ezkirotz, Osteritz, Errea eta Zai herrixka eta baserrietan eskuratu genituen ekaiak azaleratuz. Hauetako batzuk oso urriak dira, 1980ko hamarkadan aurkitu genuen zorigaitzeko egoeraren isla, inondik ere.

Herri hauetatik hegoaldera, nekez aurki zitekeen jende euskaldunik aipatu hamarkadaren hasieran: Ilurdozko gizon bat, Joaquin Garrues Goñi, harrapatu genuen 1982an Iruñean, handik urte batzuetara, 1988an, 93 urtetan hil zena, eta, jakitera iritsi ginenez, Gendulainen ere, bertan sortu Juana Irure Etxalar izeneko andre euskaldun bat bizi izan zen, baina hau lehenxeago joan zen, 1977an, 82 urte beterik, inguru honetako gure bilketa-lanari hasiera eman aurretik. Ez genuen, beraz, harekin egon ahal izateko zoria izan.

Ilurdozko jaun horri bildu geniona, aldiz, aldizkari honetako zenbait aletan argitaratu zen', baina ez lan honen emaitzak ekarri dituen 'Erro' izeneko aldaeraren

1 Hasiera batean, gure «Hegoaldeko goi-nafarreraren azentua dela-eta (hurbiltze-saiakera)» delakoan: FLV 60, 1992, baina, ondoren eta bereziki, «Artzibarko aldaera deitu izanaren inguruan» izenburuko lau zenbakitan: FLV 103-104, 2006-7, eta FLV 114-115, 2012. 
baitan, printzeak 'Artzi' deitu zuenarenean baizik. Izan ere, haren iritziz, Esteribarko Larrasoañatik hegoaldera kokatu herrixkek osatzen zuten multzoa hobeki egokitzen zitzaion, aldaera hauek direla eta, Artzibar aldekoari, Erroibarkoari baino.

\section{HIZKERA HONEN EZAUGARRIEZ BI HITZ}

Honetaz aritu gara «Erroibarko aldaeraren inguruan (2 - Hego Erroibarko azpialdaera. Lehen erdia)» izenburuko saioan, ez aspaldi, eta «Erroibarko aldaeraren inguruan (4 - Ipar Esteribarko azpialdaera)» izenekoan ondoren, esparruotako mintzairen eta beren hainbat ezaugarriren berri eman dugunean. Beraz, balizko lagunen batek, horietan interesaturik egonez gero, saiootara jotzea aski izanen luke, haietan esanikoak berriro errepikatu behar ez izateko.

\section{DATUEN TRANSKRIPZIOEZ BESTE BI}

Bokal batzuen itxierak: a eta e artekoa ä idatzi dugu; e eta i artekoa ë; o eta u artekoa, ö. Inoiz, i eta u artekoa aditu uste izan dugunean, ü idatzi dugu.

Kakoak [ ] erabili ditugu inoiz, hitzen edo esaldi motzen bat testuen barruan tartekatu dugunetan, horietan jasotzen dena argitzeko asmoz.

Ia aditzen ez diren hotsak, honen aurreko saioetan egin bezala, parentesi artean idatzi ditugu. Zalantzagarria iruditu zaigun hitzaren ondoan, parentesi arteko galdera-ikurra (?) idatzi dugu eta harridura sorrarazi digunaren alboan, harridura-ikurra (!). Halaber, pasarte ilun batzuk parentesi arteko eten-puntuak idatziz (...) ekidin ditugu.

Beste kontu bat da galdera-ikurrena. Zeinu hori ez dugu soilik galderetan erabili, berriemaileak zenbait esaldiri galdera-itxurako intonazioa eman dion hainbat alditan ere bai, baizik.

\section{SAIO HONETAKO BERRIEMAILEEN ZERRENDA}

Inbuluzketa

Apolinaria Egozkue Goñi, 1895

guraso biak inbuluzketarrak

\section{Urdaitz}

Fermina Zuazu Urdaniz, 1896

aita: Urdaitz / ama: Sarasibar

\section{Ezkirotz}

Domingo Bizkai Santesteban, 1909

ama: Setoain / aita: Larraingoa (Erroibar) 


\author{
Osteritz \\ Josefa Santesteban Lizoain, 1906 \\ ama: Osteritz / aita: Agorreta \\ Zai \\ Celedonia Bizkai Santesteban, $1899^{2}$ \\ ama: Setoain / aita: Larraingoa (Erroibar)

\section{Errea} \\ Martin Esain Eugi, 1899 \\ Josefa Esain Eugi, 1908 \\ aita: Errea / ama: Errea \\ eta \\ Maria Etxeberria Erro, 1911 \\ ama: Inbuluzketa / aita: Esnotz (Erroibar)
}

\title{
5. INBULUZKETA
}

\subsection{Apolinaria Egozkue Goñi}

\section{Eskale batengandik ikasi otoitzak $(1980)^{3}$}

[Eskale batek errezitatu ohi zuen]: «Limosna bat, in al badezakete, itxe ontako animaik balin bedago purgotorioko penetan... pena aetaik libra dezan gure Jangoikuak, bere glorie sanduen goza dezan». Y se descansaba. «Errezatiko duu aitagure batekin abemaria bat? Aita guria, zeruetan tzaudena»... ¡ Gritando solía estar! el padrenuestro entonces; habíamos, oyendo a aquel pobre? habíamos... aprendido el padrenuestro ¡Y no se olvida!

- Eta, nola erraten zuen?

«Aita guria, zeruetan zaudena, santifika bedi zure izena, betor guregana zure erreñue, egin bedi zure borondate sandue zeruen bezala lurrean ere... -como en el cielo-, zeruen bezala lurrean ere». Erran dizut, (...) gu aitagure bateki, abemarie bat: "Abe Maria grazias betia, Jauna dao zurekin, bedeiketue da, andre guzien ertëan eta bedeiketue da tzu-, zure frutue Jesus». Después...

- Eta, gero, 'Santa Maria, Jainkoaren Ama'?

Nik, 'Santa María madre de Dios'? eso es... (ez bide zuen ongi ikasi).

- Baina aitagurea ere ez duzu osorik eman; 'El pan nuestro de cada día' ez duzu erran...

2 Andre hau, Ezkirozko berriemaile Domingo Bizkairen arreba, ez zen herri honetan sortu, Zai baserrian baizik, Erreatik hurbil. Galdekatu genuenean, baina, Setoainen bizi zen, ama izanikoaren sortetxean.

3 Gai honekin zerikusia duen berriemaile berberaren beste testu bat irakur daiteke EAEL II-an (Aranzadi Zientzia Elkartea, 1990, 204. testua). 
«Eman dezauzu gure egun-, egunesko ogie, orai eta beti, barkazkizu zuk gere-geren zorrak, gu zor gaituztenei, ezkaizkiela utzi tentazioan erortzera, baizik libra gaitzazu gaiz guzietatik, Amen». Después, «Abe Maria, grazias betia, Jauna dao zurekin, bedeiketue da zure sabeleko frutue, Jesus».

- Hori erran duzu, baina 'Santa Maria, Jaungoikoaren ama'...

Orduen, Amen.

- Eta, gero, el 'Gloria Patri'?

El Gloria Patri? en castellano... El Gloria no había oído nunca; antes, había vasco, un... el amo del pueblo, y él en la iglesia también, cuando se rezaba, claro, él siempre rezaba... castellano, vamos, vasco, pero Gloria... castellano siempre. Pero ese padrenuestro aquel pobre.

\section{Ardiez oro har (1981)}

$\mathrm{Ni}$, artzaia? artzaia ni? ni, ni ez-ez; emen gizonak bakarrik artzaëak. Beira, nesako oiek? ta oiek bai, izen, izen dire artzaëak.

- Eta, non ibili dira? zein menditan?

Emen, gutxi... oianian! biña emen berëan.

- Hemendik atera gabe?

Ez-ez-ez-ez, emendik ezta atratzen batre.

- Eta, neguan...

Neguan? emengok ere ez; ;cada cual con lo suyo!

- Beti hemen orduan, berdin udan edo neguan...

Beti, beti igual.

- Eta, gazta egin izan dute?

Gazta? ez, ez... emen; gazta... iten dire or, Iragin te Eguin (sic), te oietan bai, biña emen? ardi ebek, eztire... esnasdunek, ez.

(Gurekin zen gizonezko bati, bisitaria bera, guk egin galdera dela eta): Pastora si he sido, me dice, y yo pastora no he sido, y las ovejas que se tenían... Emengo ardiek eztutele esneik.

- Eta, eilea noiz mozten zaie?

Orai, eldu en... ilbetian [ekainean], mozten dire, bai.

- Nork mozten du?

Nok? al tzakenak! gizon ebek!

- Bai? herri honetako gizonek?

Bai, bai, bai, bai; batek bertzei? laguntzen.

- Eta, eile horrekin zer egiten da?

Ella orrekin? saldu!

- Nora saltzen da, Iruñera?

$\mathrm{Ba}$, tortzen dire Iruñetik ere, Uertetik o, Iruñetik ero, tortzen dire, ta beztenaz? eman!

- Eta, zenbana saltzen da?

A! eztakit.

- Merke ala kario, garesti-edo...

Eztait!... orai bada ardi... merke? batre? ezta, ezta. (Alaba Encarnari eta bisitariari):

La lana, a cómo se vende entero... a cómo quedó pero, todos los años igual no, tampoco... urte guzietan ez, eztire beti igual saltzen. 
- Eta, ardiak markatu egiten dira?

Markatu? ez, ez.

- Belarrietan ez diete egiten koxka bat edo zerbait, ezagutzeko?

Ez, ez, ebaki ez. (Besteei): Las ovejas ¿ya están marcadas?

(Bisitaria): Aquí no, en Eugi sí hay algunas marcadas.

Emen guria pakarrik dire, ta... denak guriak!

(Bisitaria): Hacen la selección para la leche, precisamente, o sea, ovejas de leche; aquí son churras y en Eugi son latxas, más de leche; como en Gipuzkoa ¿por ejemplo?

Y en Iragi también...

- También hay otra que llaman 'rasa navarra', ¿no?

(Bisitaria): Sí, parecida a esta, a la churra, pues eso es igual, es la misma casi, la churra, sí.

\section{Errokatu ez baina josi bai (1981)}

- Zuk errokatu duzu?

Ez-ez, nik eztut errokatu batre.

- Eta, hemen izan da errokatu duenik? herri honetan?

Ez! emen ez, emen ezta errokatu batre.

- Ez zen biltzen ligua eta algodona eta?

$\mathrm{Ba}$, ez, ori guttio. Ellak, ellariek zerbait ere bai, makiñe bat izeten e tzire... or, Aezkoatik ero tortzen tzire... makine batzuk; arreki? errokatu te aëek kaltziñe, kalzetinek iten oiendako, biña beste gañerakoik ez.

- Beraz, ez duzu errokatu...

Nik ez, nik eztut errokatu, ni, nik yosi, Nik zautu dut, emen ¿cómo le diré pues? lino hay llegaö yo, a sembrar.

- Ligua?

Liguä; ta, nola... trabajatzen tzen ligua. T'ori hi-, ari oiek? Iruñea(n), en casa... en la zapatería ¿cómo era pues? Goñi me parece que era, la zapatería.

- Erran, erran ezazu euskaraz...

Bai; arata, an ematen ginue? ta an... tejitui $(\mathrm{k})$ eramaten nituen, tejituik...

- 'Ehundu' edo, nola erraten zen?

Errietan ere izeten tzire, la Casa (d)el Tejedor nonbratzen da Etsaiñen ere, an ere iten tzire nunbäit ere... pero en otro sitio también ya había pues tejedor, de Egüés o... por ahí también hay, bai, izeten dire, bizi dire!... biña, emen ez! emen ez.

\section{Ogi egiten (1981)}

- Ogia egin duzu?

Bai, bai, ogie bai.

- Nola egiten zen? erran ezazu ongi, hasieratik beretik, e?

Lenbizik? garie; gero? eman errotara; gero?... gero io, gari ure io? ta, gero... ogie iteko bezperan? eiten gindue... tornuen! ementxe iten e... itten tzen te! emendik? e... itxe ontan, emen. Ta gero? arratsëan? orantza; orantza, ta gero, biramonian?... ya, goizea ta, in bia bidire, masiak.

- 'La masada', ezta? ogiak eta opilak egiteko, ez? 
Opila, ogiek, ogiak.

- Eta, ogiak non ezartzen ziren? ohol batean edo?

Bai, oratx! no, pal horno ¿cómo le diría yo?

- ¿Una tabla o así? ohol batean edo? lehenbizikorik?

Lemizik, arto batian iten ginue; gero, bi orduz eo orrela eoten tzen? bere... bere orduen. Gero? labian biztutzen bigindue(n), ta... or beian d'or. Lenao? sukeldie zen lekuen? ara labia, an dao, labia oraño. Ta gero, sartu labian? ta ogie inik.

- Bai, baina sartu nola?

Nola? pues, ola batekin.

- Eta, ateratzeko?

Atratzeko ere ola berian!

- Eta pala bat ere bazen, ezta? eta erratza eta...

Pala, palak, palak eo? pala... pala arizesköa, aritze.

- Ogia zenbat egunetarako egiten zen?

Ja! astean eun betez, aste guziko! igande guziek eiten ginuen...

- Erran dugu erratz edo eskoba antzeko zerbait ere bazela, ezta?

Bai, ta... zerekin? belar tzakarr oiekin... (bisitariari): pa barrer, la escoba dice, y... ¡con hierbas viejas!

- Belar zakarrak?

Belar zakarrak, ta... labia bistutzeko? orrea, orrea; berotzeko ori? labia? orrea.

- Ez dizut galdetu 'levadura'ri nola erraten zaion...

Orantza. Ya, azkenian, orantzak ere, nola ogiak egitian, Iruñetik edo ortik kartzen tzire orduen, ogi obia itten tzä, ogia... atratzen tzigute; bestenaz? iten delaik ogie? pues, puxk'et olaxe utzi? te arreki, iten tze bezperan... hacer la levadura, arrekin in? te, arreki.

\section{Esaera (1981)}

Mayo fardo, ogi t'ardo.

- Mayo fardo? hori zer da? zer da 'fardo'?

Fardo quiere decir, mayo... siendo blando, pan y vino; pero... hoy les he dicho: «No sé pues»...

- Eta, fardo hori zer da? euskara?

Klaro! fardoa! bai, bai; ogi t’ardoa, baña...

- Erran dute hilabete honetan euri aunitz...

Euri aunitz beña... otzik eztu!

- ... bota behar duela.

Otzik eztu iten ez, beño... denbora makurrao... orai biño, zautu dut nik.

\section{Haur-jolasen inguruko apurrak (1981)}

- Haur edo ume zinelarik, hemen nola jolasten zen?

Aurre? 'criatura' es.

- Bai, haur-denboran nola jolasten zineten herri honetako karrikan?

Karriken... noreki?

- Jolasten, bai, zerekin edo zertan?

Bakarrik; bai, ezta aurriken emen e! ezta... 
- Ez zineten ari kaniketan, tabetan, edo...? 'juegos de niños' quiero decir.

Sí, juegos de niños, pero ¿qué juegos de niños? aquí unos sobrinos suelen venir de (...), a jugar a pelota; aquí no hay un crío, el más joven de este pueblo...

- Erran, erran ezazu euskaraz.

Zanbalaz!

- Bai? eta nola?

Nola? soka bat paratu? te, «Buluno, buluño... bulungo» solían decir ta, ¡hala! zanbala, zanbala.

- Zabu edo 'columpio' bat bezala edo? soka bat dilingatu arbola batetik eta...

Bai, bai, bai... ala dire, bai.

- Eta, zer bertzetara? tabak, kanikak, zibak...?

Ze... biar nik? orai, kartetan edo, naipe o... Bueno, pa decir 'naipe' ¿cómo diré yo, pues?

(Daniel, berriemailearen semea): ¡Porrazo!

¿A qué juegos? lorean, también, lorea; ¿la flor? «Vamos a jugar a la flor», lorea, lorëa. - Tira, konta ezazu nolakoa zen jolas hura.

Iru... kartetan, lorëa? iruek, flore bateña, iten tzire; flor, juaten tze?... atratzen bazire iruek, flore batetik? flor; beña? zazi!

- Baina, hori kartetan zen. Eta haurrak, karriketan, nola?

Launa, beñä... ameka ume azi, ameka... izen gindue gu, bertze ameka, bertze... bertze aizpe bat? gero, Erreako ori? bertze ameka; ze in biar gindue? maindereköak garbitu, bakizu? ori ze gure ju(e)go oi, jugea ori ze, jeje!... orduen? ta titi man? ta, azi, orduen etzen mamen-, mamonik eta kosa ez, etze, etze...

\section{Herrian zenbat familia eta beste zenbait kontu (1981)}

- Zenbat familia bizi ziren hemen, zu haur ttipia zinelarik?

\section{Errien?}

- Herrian, bai; orduan zenbat familia ziren?

Ba! emen, orduen, iteko konta-, kontatutzeko; emen? bat, bide, iru, lau, borz... sei, zazpi... zortzi o bederatzi bai.

- Eta, orain, sei bat?

Orai? cuatro, lau; orei lau.

- Orduan haur ttipi asko izanen zen...

Klaro! orduen? apezak maten tziote, mezonduan? eguardi bittertio? bueno, aurrei? etzen enseñatu're; eskola... izein tze bai, orduän aqui, eskola; biño, gero...

- Apeza nongoa zen?

Nongöa?... bai! anbertze izen dire!...

- Apez euskaldunik izan da hemen, zure haurtzaroan?

Uskaldune? ez... ez.

- Orduan katekesia ere erdaraz emanen zen...

Klaro! erderaz, erderaz. Bai, apezak bazakite? uskeraz? jeje! berendako etzakite ta guretako, ze enseñatu ute?

- Eta, zure senarra nongoa zen?

Erreakua.

- Euskaraz ongi jakinen zuen... 
Bai, klaro, yakinen! biño ya, emengo gaztek?... gure umek eta, anaiek eta, oiek ere... etzute segitzen? ta, akabo!

- Eta, ezkondu zinetenean, senarrak eta zuk elkarren artean bai...

Ez, ez, elkarrekin etzen ez, ez, ez ginduen ya....

- Ez? erdara?

Erdera.

- Eta, hamaika ume izan duzu?

Ameka, ameka... ameka; ta... guk bertze ameka, eta... ori... an, Erreati torri die denak, or badakizu ze... orai, Uarten baitire, andik bertze ameka!

- Eta, hamaikak bizi dira?

Bai, bai-bai, ameka bizi dire.

- Non? Iruñen, Uharten, herri hauetan?

Denetan! denetan... denetan.

\section{Eultziaren ingurukoak (1981)}

- Eultzia bukatu ondoan, zer bertze egiten zen?

Pues, pala oieki! pala ok-, oieki... da aizieiki? garie, garie... gariä, bueno, juaten bada, aizia torri da? aizien aldera, ta bertziak? montonera.

- Eta, hori non egiten zen?

Emen e! emen ere? emen ere denak.

- Lekuari nola deitzen zaio? larraina?

Larrañe, larrañe, bai. Bildu, dena, ta gero, aizia balin bäda...

- Baina, eultzia egin aurretik garia larrainera eraman beharko zen; zerekin?

Zerekin eman? pues, kanpuan eiten dira, gariek eta denak ara? larrañera.

- Bai, baina larrainera eramateko...

Karruäkin! karruäki(n); garie barin beda? garie, ta gero? barin beda garagarra? garagarra... delaik.

- Orduan, eultzia egin...

Eultzie.

- Eta, haizea etortzen zelarik, orduan pala horiekin gora?

Aizeratu, aizeatu; artu... aga bat? erdien? te, pikorra alde bat? ta, beztzia? bertze aldera.

- Bertzea zer zen? lastoa edo? 'la paja'?

La paja, lo que sea; si es paja, paja, si es malkarra, malkarra.

- Eta, 'paja' nola erraten da?

Aotza.

- Ahotza edo malkarra?

Malkarra? malkarra ${ }^{4}$, pero la paja de... la paja, aotza.

- Eta, malkarra zer da?

4 Azkuek honela dakar: $2^{\circ}(\mathrm{BN}-\mathrm{s}, \mathrm{R})$, paja de beza y gerón (sic) : paille de vesce. Eta Orreaga Ibarrak honela: iz. malkarra <Paja de las legumbres y especialmente de las habas>. Malkar ura biltzen ginuen ongi (Mez) (Ibarra, 2007, 97. or.). 
(Semea): Es un grano parecido al trigo, otro grano que da pa comer el ganaö (...), otra clase de semilla. Las habas, las habas mismo, pues tienen la part-, ¿lo que le quitas a las habas? es malkarra; no es lo mismo paja que malkarra. Varias clases (...); y en el otro, quitándole la semilla que era, malkarra.

- Y hay un aparato para hacer la trilla, ¿no?

¡Trilladora! (...), porque aqui vino muy tarde.

(Alaba): Sí, pero trilladora en el año cuarenta y ocho había aquí (...).

(Apolinariari): Horrek bazuen izenik euskaraz?

Trilladora? e! orduen, etze, uskereik e, etze orduen.

(Alaba): Pero, en el trigo también ya separaban otra cosa... ¿qué era, qué era aquel trigo dentro del barbudo? pajudo, que le dicen (...), un trigo que tenía una cabeza como un...

Burukek, oiek? txerriendako, txerriendako.

- Zenbat larrain zen herri honetan?

Ba! bakotxak bere larrañä, bai.

- Eta, zerekin biltzen zen garia edo dena delakoa? igitaiarekin edo?

A! klaro, oiek, ta gero... tallak, oeki... a la talla, ¿cómo se decía?

(Semea): ¡Pues talla! guadaña... siempre talla pero, pa comprar... cuando vas a pedir siempre entienden guadaña.

Igiteak!... orrek, patzen tzire(n), goiti aldetik... iite? bueno, pionak tortzen tzire, garie moztera.

- Eta, ez ziren eriak babesteko gauza batzuk? 'cazoletas' edo?

Cazoletas.

- Euskaraz nola?

Tsoketak, tsoketak...

\section{Bidegurutzerainoko bidea (1981)}

- Noiz egin zuten, noiz asfaltatu zuten bidegurutzerainoko bidea?

¿Qué años llevará la carretera?

(Semea): Pues llevará, cuarenta y tres o cuarenta y cuatro.

Berrogei igual; berroeite lau dio! berroeite lau.

- Lehen oinez ibiliko zineten beti...

Je! abrëan tta, beti... denek, oñez? te, abreik etzuenak? oñez, biñä... denek bagintuen e... abriak; batek mandoa? bertzeak zaldiek? beztiak biorrak? o astoak?...

- Eta, gauzak eramateko ere berdin, ezta? astoekin eta behorrekin eta...

Gero, iyotzera emateko gariek eta oiek? emengo... errotako? berek egultzi, ibiltzen tzuzte? iru-lau mando, beren... faleaki te, erraten gindue: «Ya viene... febrero», erraten gindue. Ta, tzakuek? guk ere... guk, bide, bertzek bertze bide, bertzek bertze bide, maten tziote? ta, io? ta, gero kartzen tzitue berak, beak. Or, errota ortan, or gelditzen tze, etxe errota, or, orai or baite ostatuik, or, or tzire? ostatuik.

\section{Ogi bedeinkapena eta fuesen aipamena (1981)}

- San Juan egunean zerbait egiten zen hemen?

San Juan?... argitu orduko ilune.

- Ilune? 
Nik er'ori egosii tut ${ }^{5}$, «San Juan egune, argitu orduko ilune»... es eso, pal día de San Juan, pa cuando amanece ya oscurece, eso en vasco, ¡no sé por qué diríamos!... como hemos dicho... mayo: «Mayo fardo ogi t'ardo".

- Eta, egun hartan ez zen ezer egiten?

Ez-ez-ez-ez-ez, batre; Esañen, Esañen eite-, eiten tzuten festa? ta, al tzaikena... arara juan? ta...

- Surik ez zen bizten?

Ez, ez, ez.

- Ez zen deus egiten San Juan egunean edo bezperan?

(Gaizki ulerturik): Ereki, ze?... San Juan egune ze, yatekoak edo, ereki o ala? bedeiketu?

- Ez, ea zerbait egiten zen.

Bedeiketu? menturez? eztakit, eztakit zer.

- Bedeinkatu, San Blas egunean egiten da, ez?

(Semeak elizan banatzen omen zituzten olatak aipatu zituen).

Ogie ere? ogi bedeiketue.

- Eta, nola, zer erraten zuten?

Bueno, ogie, itxetik ematen ginue, bueno, astëan o... yei betian aitte ${ }^{6}$ batetik, bertze iendian bertze itxetik, ogie ematen tzute txaskira, ta... uzten tzute. Ta gero? ematen tzute... sakristiera? ta bedeiketze zue apezak? ta, ba... etzakite nori... tokatzen tzaion, gizon oiei eman? ta, nabaleki? iten tzute, koxkor batzuk ola? ta, batek? 'la paz' edo nola...

(Semea): Sí, la paz, la paz, la paz...

La paz y el katillö. Akabatzen tzelaik meza? geren mutikoikin? tortzen tze... fuesetara apeza? ta, bi sosekoa maten bagëndio? sosa urä, mutiko aieki? itzuli, sos batengatik, torriar tzue errezo ittëra. Ze mixerie zen orduen ere! ze miseriä!

\section{Korpus Eguneko prozesioa (1981)}

- Prozesioren bat egiten zen?

A! bai, Korpu Kristi egunian... bai, bai, orai ere bai!

- Nolako prozesioa da? zer ateratzen dute elizatik? lehenbizi gurutzea edo zer...?

Gurutzia? palioan, palioen... bean? o, Gure Jauna! ta, aldareak, e... paratzen dire... ärrien ere. Gero, karrikek, garbitzen dire eta botatzen dire... junkuak, erraten dute, inik ola; klaro! man bueltak? erri? leioak, denak... beztitzen dire.

- Maindirez edo arropa zuriz?

Bai, arropa xuriek!

- Zein ateratzen dira? monagillo bat eta apeza?

Denak, denak...

- Eta, gizonezkoak eta...

5 'Hausnarturik dut' izan liteke hori, agian, zein testuingurutan dagoen ikusita.

6 'Itxe' da hori, testuinguruari behatuz aise antzeman daitekeenez, baina idatzi bezala aditzen uste dugu.

144 Fontes Linguae Vasconum (FLV), 125, enero-junio, 2018, 133-190

ISSN: 0046-435X ISSN-e: 2530-5832 
Denak, denak; badaile ortan? jendea?... denak! jendie bizi da? ta, elizea, akabatzen deleik meza? atratzen da, bere palio edo... bidean apäza? ta bere estazioan? iten tu bedeiketu te o... gero, aldarëak patzen diren... itxetan? emen beian? gure itxean, beien paratzen da, or maian? ta or. Bedeiketu? ta... gero? juan elizera? ta aka(b)o.

\section{San Martin eguna (1981)}

- Herri honetako patronoa nor da?

San Martin.

- Egun horretan zerbait egiten da?

Ejeje!... bazkari ona.

- Deus besterik ez?

Ez, ez; gutxi, gutti, gutxi ba, ori bai, meza bai.

- Eta, gero zer? musa edo musika edo...?

Gu? musean?... ta dantza, klaro!

- Nork sonatzen du musika? musikariak kanpotik etortzen dira?

Tortzen dire, tortzen dire're bai.

- Denbora batez gitarrarekin eta kantatuko zuten...

Ez-ez, orai, orai etortzen dire bai, majoaokoak, biña orai? ezta itxetan ta agai i(b)iltzen ere; itxe batian paratzen tute?... an biltzen dire? ta an...

- Denbora batean bai, etxeetan, gitarrekin eta...

Bai-bai-bai; itxiak itxi, itxiek itxi.

- Eta, zer kantatzen zuten?

Ze kantatu? pues ze kantatiko?

- Koplak eta jotak eta...

Eje! klaro!

- Ez zara ezertaz oroitzen?

Ze gantu? gatz at (?) edo bi edo iru itxe batetan? ta ala! bertzea, ta gero? afaltzera! Afaldu? te, gizona o... gizon oiek guziek? yokure!... itxez itxe, beren itxan, juntatu te... egun betez itxe batëan, bertze... egun betez bertze itxean, yokuen. Biño? maiz, elurrakin egiten da, San Martin eune...

- Noiz da San Martin eguna?

El once de noviembre.

- Eta, batzuetan elurra izaten duzue hain goizik?

Bai, bai.

- Ba, elurra delarik, etxean baino hobeki inon ez da egoten...

Je-je! etxean! elurre... gutti, eurie bai, eguri tte... otza ta, denbora txarra.

\section{Zerri-hiltzeaz (1981)}

Nola zen? bai, orai, nik eztut ikusi biño, orai asi dire, tiroak botatzen diote, txerriei o. - Ez, lehen, lehen...

Len?... ta, iru-lau lagun o, bildu? ta artu txerrie? ta... bueno, mai betera bota?...

- Hartu, bai, baina bakoitzak nondik?

Bakotxak berak nondik!... eje! tzerrie... txerrien gañera iyeten dire? ta batzuk, burue? ta bertziatzuk or, besöak? bertzeak ankak; klaro! ze biaute? 
- Bai, eta horren ondoren, zer?

Odola? ja! kanabiteki!

- Zer, kanabita sartu?

Klaro! lepapetik, lepapetik... nabala... bueno, entra? sartu? ta mazteki et, bañera batekin, odola artu? te, tzerrie ¡hala! in sue? ta, erre! erre. Ta gero...

- Zer erretzen zuten?

Bilöa!

- Eta, gero, bañera horretan biltzen den odolarekin...

Tripotak, tripotak; ta gero... karrikera atra? ta, an sue in? kixkorratu? ta gero, ur beröa emateunte? ta, ur bero arrekin? gero, dena garbitu txerrie!... Gero, tripek atra? ta, goitire, afaltzera.

- Eta, txerriaren haragiaz zer egiten zen?

Tzerrien äregie? ja! biramonean. Odol arreki? tripotak, ta, gero? egunez, sekatzen delaik? in... pusketu tzerrie, orra, ola pusketu tzerrie? ta, puxkäk? man gatza? ta beste gañeraköak? in, txistorrak... ta solomoak? yan segido.

- Eta, zer beste egiten zen? lukainkak, 'longanizas' edo... nola erraten da?

A! oiek die, txistorra tire, longanizak... txistorrak.

- Longaniza ez da bertze gauza bat?

Ez, leno iten tzire... txorizoak iten tzire peña, orai, urdeiak eztugu yan nai? ta urdeia, botatzen diote... bueno, eiteko txistorrak ta, ara eiteko... txorizoki, ez in? te txistorra yao.

- Eta, 'jamón' nola erraten da?

'Magra' le solemos decir, magra... azpiek!... azpiek. Tres cosas hacíamos antes: birika, con las cortezas, y magro? chorizos.

- Bai? birika zerekin diozu?

Birikë, bai, azaleki, azaleki; gero? txorizoak... magroeki, magroeki, ta... da gero, txistorrak?... urdaieiki.

- Eta, txerriak, nabala sartzean, zer egiten zuen?

Zer egiten tzue? ze in biar tzue tzerriek? alkien eon... eon tze.

- Baina, oihu edo?

Bai, oyue ejeje!... oyue? oyue iñin tzue beña, fite... ixil-ixile, itzultzen? ta, sartu bazen... laister...

- Nabala?

Nabala... iten diote? ta, akabo tzerrie.

\section{Hegazti harrapariez bi hitz (1981)}

- Zapelatzak eta miruak zer dira?

Diga usted en castellano, cómo son...

- Cernícalos, milanos y esas aves de rapiña; badira hemen?

Sí, sí.

- Eta, zer egiten dute horiek?

Ze iten dute oiek? arrapatzen baute, oiek... azurien bat, o or, ezin... sortu o balin bedaude? aiek yan.

- Eta, oilo eta txiten atzetik ez dira ibiltzen?

Ez-ez, ez-ez... eztira or arrimetzen.

- Eta, animaliaren bat hiltzean, orduan etortzen dira? 
Bai, bai-bai... arrano? ¿cómo se dice pues?

- 'Arrano' puede ser, sí, 'buitre'...'

Arranos, los arranos, todos... «Andan milanos»-no sió ${ }^{8}$ «carne sienten». Eso... ya suelen decir aquí.

\section{Intxaur, basaran eta besteren aipamen laburra (1981)}

- Intxaur-biltzea egin da?

Bildu? bildu?

- Bai, badakizu zer diren intxaurrak...

Nueces.

- Bildu dituzue? hemen bada intxaurrik?

Bazire; orai, zazi!

- Horiek ateratzen dira...

Bai, bere... kaxkaraki, bai.

- Nola erraten zaio horri?

Eztakit e! ¿cómo era pues? (alabari): A la cáscara de nuez ¿no te acuerdas tú, cómo le llamaban?

(Alaba): ¿Pero cuál, a ese verde griba? ¿afuera? kutsarana, ‘el gucharán’ le solían decir; ahora, eso sería...

- Eta, nola biltzen dira intxaurrak?

Pues, arboletaik botatzen tzire... lurrera? ta gero, zanguekin eo, kendu? te, aiek garbitu te bertziak? bota, esietara.

- Bota, nora?

Exietara o, errekara o...

- Eta, arboletik botatzeko, zer egin behar zen?

Norbaitt erritan egoitexu9... ieten tzire, ta makillekin zinpi-zanpa, ta gero bertzenaz? utzi...

- Berez?

Beren... beren kase o, sekatzen tzirelaik? eortzen tzire, t'erori bezein... fite? pelatu iten tziuzte.

- Eta, patxaranak ikusten dira hemen?

Ez; lorean daudelaik, tortzen dire Iruñen, Iruñeko... jende guzie dui kabe; oi-oi oien salsa! garbituik? eta emen (...), paxaranak?... jende guzie deil, Iruñetik onata tortzen dire.

- Orduan, patxaranik bada...

Bai, zenbait itxetan dire beña... Orai? karakolak, arras afizionatui taude jendëak, karakolak biltzera; emengöak eztugu ni miretzen sikiera? ta, biltze oietaik? ta jun dire. Xixek? dui kabe... badakizu, xixek zer die; eztara (sic) igual, biño...

7 Nafarroako oso eremu zabaletan arrano gazt. 'buitre' da (edo horrela esaten zaio, behintzat) eta ez 'águila'.

8 Gazt. 'no sé yo' bide da hori.

9 Balizko hitz honek beste esparru bateko 'egoiten duxu, egoiten dituxu' oroitarazten digu, baina honelakorik aditu ahal izateko urrun samar joan behar da, Luzaide-Arnegi aldera gutxienez. 
- Eta, etortzen dira kanpotik hona, e?

Klaro! betti aldeti, eozein lekuti, eune pastera; karretera?... «Ongi torri» ta ya está, esaten dio... jende ori.

\section{Txorimaloak (1981)}

- Nola dira, txoriak uxatzeko, baratzeetan paratzen diren 'espantapájaros' horiek?

Mozorroak.

- Orain ere badira?

Orai? ez-ez, orai ya ezta bat e; tipule bat ere eztaola plantatuik ee erri ontan orai; zetako mozorroak? zetako zu?

- Denbora batez bai, baziren...

$\mathrm{Ba}$, orduen bai.

- Ba, orain ere gutxiago arrimatuko ziren txoriak...

A! ya eztia, aextian e, erran baitut, pantalonak eta paratu? te gero, arrimetzen tzire, oiek... baratzian igual, baratzëan igual, mozorro paratu? te... txoriek, yan denak.

- Mozorro haiek nola egiten ziren?

Je! eztakit, nola izein tzire.

- Makila batzuk gurutzatu, arropa zahar batzuk beztitu eta... horrelako zerbait?

Bai, o paperak o alako zerbait, paratu... makil bätzuk? eta, aizëak eta ibiltzen baitute! oialak edo lo que sea, oiala o papera o... edozein gauze!... eozein. A, iduri!... bakit zer die, e iduritzen tzai(d)e, eskapatzen tziela, bai! gelditu bai, izan tzirela!

- Errespetu gutxi izaten zuten...

Eta ain gutxi; gutxi? batre.

\section{Ameriketara joandako anaiaz (1981)}

- Ameriketan baduzu familiarik?

Ez, Ameriketan eztut iñor ere.

- Baina, izan duzu?

Bai, izen dut: anaie... anaiä.

- Nola erraten da gehiago, 'anaia bat' edo 'anai bat'?

Anai bat, anaiä. El cerero de Erro ¿ya conocerá usted? ¿el panadero?... orren anaia, Ameriketan, il tze, orren anaia; anaiai? bai-bai, anaia, an il tze.

- Eta, non egon zen? zein lekutan? Kalifornian edo...

Mejikon, Mejikonian.

- Zertara joan zen hara?

Zeta? je! ardiekin te, o...

- Artzai.

Artzai, artzai.

- Urte aunitz pasatu zituen han?

Bai, pasa zitue ogei bet urte o... orduen? orduen juan tzire... ori, bizkerra? Jesús! soldaö... eskapaö ¿cómo se llama?... ta gero? kunplitue (...) denbora? torri ze. Bertzoat Frantzien, zarren-tzarrena, anaia, zarren-tzarrena, ure Azparren, ure igual. Ta an il tze, an, an... azkenean an berean... akatu ze; panadero izen tze emen. 


\section{URDAITZ}

\subsection{Fermina Zuazu Urdaniz}

\section{Inauterietako lelo ezagunaren hondar desitxuratuak (1984)}

«... korde, zuri-zuri barkillokeri, San Gregorio Coronado, obispo de...»

(Alaba): Pero eso es en castellano; el papá nos cantaba en vasco: «Urruti kozko-», ¿Cómo es?

- Iñaute koxkote?

(Ama-alabak): Eso, «tzerri tzar bat dute, ez dute ezer, txarra ez dute, ezpaña guti faña, gutti-gutti el dute». Y te daban castañas...

(Errepikaturik): «Ez dute, ezpañan guti mañan, gurtzi-gurtzi ez dute!»... decían; algo así.

- 'Ezpañan gutimañan'?...

«Gurtzi-gurtzi il dute». Mozöak, denak!

- Mutilak eta.

Bai, ala...-morda(t)zera.

- Haiek bakarrak etortzen ziren? neskak ez?

$\mathrm{Ez}, \mathrm{ez}$, mutikoak denak, bai. Ta ya an, ongi almorzatu? ta gero, pimientoak ta ogie, ta ardoa. Y atsaldian? ¿en el pueblo? asaban, los pollos... Erre? pimientoak erre, y gero? gisatu, kazuelan, grande, ta plazan, bailea, bailëa.

- Bai? dantzara joaten ziren?

Bai, ya aek... xan? ta ardoa ta denak... gargero, ¡todos los hombres del pueblo!

- Herriko gizon guztiak, e?

Bai, bai-bai.

- Eta, musikoak nongoak ziren?

Len? lemixikoa... de Aoiz; an, an también se irían? pa el día San Miguel, ya no sé si habrá paraö, si habrán pasaö, si habrán cambiaö.

- Lehen aipatu dizudan Olaizko gizon zahar horrek erraten du bera ere, gazte zelarik... Bai.

- ... joaten zela inguruko herrietara, festetan, gitarra jotzera.

Ya, ya, ya, ya; ori... nik ere, zaun-, ya, ya le conozco.

- Bai? ezagutzen duzu?

Bai, bai, bai; bueno, faten naiz, ikustera, bai.

\section{Zerri-hiltzeaz (1984)}

- Zerria hiltzeko, zer egin behar zen?

Ze in biaurte? pues... arsaldian? bazkarra (sic); ez, eztute... (t)xaten, ta... ¿al día siguiente?

- Biharamunean?

Bai, il.

- Nola hiltzen dute? txerria hiltzeko zer egin behar da?

Madero gan, paatu? ta an, bota... tzerrie! ta iru... gizona o ola? iruki.

- Nondik iduki? besoetarik edo? 
Bai, bai, ta kutxilleiki? meter, ta bertzea...

- Nondik sartzen zioten?

En la entrada, entradan.

- Ez, baina buruan edo gorputzean edo zein lekutan?

Kuelloan.

- Lepoan?

Bai, y gizona? no, mazteki bat? ola, iten du... esto.

- Odola?

Odola bai, ta kedatzen da... cosas grasas, aquello para que no cuaje... sangre. Ta, gero? ki-ira, kii... sue? in sue? ta bota tzerrie? ta, tostatu billo.

- Biloa, e? zerekin?

Ollagaiki.

- Eta, andreak zer egiten zuen odol hartatik?

Morzillak.

- Nola erraten da 'morcilla' euskaraz? 'odolki' edo 'tripota'?

Tripota. Y gero? ongi garbitu, txerrie, ta... abrir, ta dena sacar.

- Ireki...

Bai-bai, eta maztekiä, artzen du, bañeraiki dena, ta ugeldera finkätzera.

- Eta, gero, nola paratzen zen txerrie?

Kolgatuik, y... por las, a $(\mathrm{t})$ saldian? o al... al bertze día? partitu.

- Partitu; eta gero, hortarik ateratzen ziren urdaiak eta...

Bai ta, kendu... lemixikoik kendu tuzte... nola zaio eso?... lomak (sic), kostilla ta de eso? quedando, bakarri-bakarri, urdëa, ¿y eso? salatu. Ta cada... zortzi eunez? «Kar beza» y bertze... otros zortzi egunez? bertze, otra vuelta, ta gero? atra, labatuik? ta korra.

- Apezari egiten zitzaion presentea?

A! bai, bai; gure etxëan ez, beñe en el pueblo bai. Gur'etxëan, mandábamos a los que no mataban, jente pobrea bazen, ta, arrek bai, baño a los que mataban no. Bai... a quien no mataba, y allí, a todos agradecían.

\section{Lixiba egiten (1984)}

Konporta, y lixu... e, no, ¿río?

- Ugaldean?

$\mathrm{Ba}$, ugeldian, arropak garbitu, ta gero? etxera, ta pazten... poníamos en el cu-, ori.

- 'Paratzen gindue'?

Bai, y ta gero? agua, limixkua agua? tibia.

- Epela?

Bai; gero? erbitu y... ¿toda la noche?... ola, ta al día siguiente...

- Gau guztia horrela egoten zen?

Bai.

- Eta biharamunean?

Berëamonian? atra? ta, ugeldera! garbitzea, tenditu.

- Tinaja barruan zer paratu behar zen? hautsa?

Autse parat-, (...) bota de arriba agua, botatu? ta...

- Goitik? zerekin botatzen zen? 
Con, de, fuego! kalderati! cocer? ta... bertze ala, alrededor? ta para... ponían, garbitzeko arrep-, arroba, esto arrepak? zenize! nola erten da?

- Hautsa.

Bueno, zeniza, bai; ta aquello, bota por encima ta, garbitu. Y luego, de abajo, atra? ta... kubo at o, a un cubo.

- Kubo batera?

Bai; gero, andik koji? ta, berriz kaldera, en la misma agua. Ya, a punto de hervir, vuelta tras vuelta. Y ya, cuando ya... estaba que parecía, egozi?

- Egosirik zegoelarik? orduan zer?

Orduen, tapa? utzi, hasta... el día siguiente a la mañana. Gero atra? ta ugeldera, garbitzera.

- Eta, arropa nola paratzen zen? zer paratzen goiti eta zer beheiti?

Goitian la ceniza.

Honetaz landa, andre honi eskuz hartu genizkion hitz urri batzuk dakartzagu:

úrde lóya (= 'zerri zikina', irain edo laido gisa erabilia) / litro at ólioa / arrótzeak / bílloa (= 'pelo') / lárrie eta algórta (= 'sábana') / atórra / maindíre (= 'manta') / burúte (= 'rodete', ferretak-eta eramatean buruan jartzen den kuxina) / kozkóte (= 'hoja? de maíz’).

\section{EZKIROTZ}

\subsection{Domingo Bizkai Santesteban}

\section{Ezkirotzen bost familia (1986)}

- Zu sortu zinelarik, Ezkirotzen zenbat familia ziren?

Pues, bat, bide, iru, lau... bortz. Lau? errien, eta bertze familiä bat? eliz ondoan, elize dao...

- Apartexeago.

Aparte, bai, ta an bertze familia bat, ze... Ez-, Eskirozkoa ure e, bortz, arrekin bortz. Ta orai? eztagit, iru... familie izein diren e.

\section{Herriko Esaindarrak eta inguruko lagun batzuen aipamena (1986)}

- Ilurdozko artzai batekin ibili zinen, ezta? (Ezkirozko batekin esan beharko genuen) Ni? ez-ez-ez, ez.

- Nik uste nuen Ilurdozko batekin ibili zinela, Juanito Esainen aita izanen zen...

A!... beño Ezkirozen, Eskirotzen.

- Eta, hura ez zen Ilurdozkoa?

Ze? gizon ure?

- Bai.

Ez, Erreaköa, Erreakoa ze.

- Juanitoren aita?

Bai, Errekoa, Erreako, Erreakoa ze ure [Miguel Esain], Erreako Pauloneköa, bai.

- Eta, harekin noiz ibili zinen? zenbat urtetakoa zinela? 
Pues, artzai... ibili nitzen orduen.

- Hiru urte haietan, ezta?

Bai, ure... eoten tze beren ardiekin, tä gu, ni? gu gure ardiekin, klaro.

- Eta, harekin egoniko denboran euskaraz mintzatzen zinela eta...

$\mathrm{Ba}$, kasi beti, bai, arrekin bai. Gero, torri nitzen etxera? pues... etxean, eee!... ala, yardukitzen nue erderaz.

- Baina, harekin sostenitu zenuen pixkat, e?

Bai, bai, bai, bai.

- Hark kasik hobekiago jakinen zuen euskara erdara baino...

$\mathrm{O}-\mathrm{o}, \mathrm{ze}$ ? gizon arrek? bai! aunitzekin! aunitzekin e, obeki euskera, klaro!... bai-bai.

Ta bere semeak ere denak badakite, aek, uskeraz.

- Bazekiten.

Bai, bai.

- Orain ez da han inor bizi?

Ez, nik uste... ezta bizi, batre, ninguno.

- Duela denbora gutxi hil ziren bi anaia eta haietariko baten emaztea...

Bai, bai, bai, bai. Emen il tze bat? ta bertze bat Larrasoañan? ta, beste bat eztait ori.

- Ba, nik banekien, bai, bazela Juanito Esain bat.

Semea, arren semea; orren aite ze... nereki artzai... egoten tzena.

- Eta, horiek Ezkirozkoak zirela diozu?

Bai, Eskirozkoak, denak; amar, amar anaia, zire, denak Eskirozkoa ta. Denak ba-, badakite, bazakite, euskera, denak.

- Bazekiten.

Bai, bai, bai, t'ait $(\mathrm{t})$ etamak ere bai.

Ezagutzen dut Ilurdozko gizon bat, laurogeita hamabi urtetan dena.

Ori, beño bizi de?

- Bai-bai-bai, Iruñeko salesianoetan, fraide legoa da, eta, badakizu, iruditzen zaio denbora ez dela pasatu eta erraten dit, Ezkirotza joanez gero, familia euskaldun bat opatuko dudala...

Ez, ez-ez-ez, orai ez.

- Ez, baina bera oroitzen da mutikoa izan zen denborako...

A! bai, bai, bai, orduän bai, orduen bai.

- Orduan bai, eta iruditzen zaio denbora ez dela pasatu.

Eztela pasatu, klaro, klaro. Ez-ez, ez-ez; orai ezta... bat ere ezta izein e, Ezkirotzen, uskera den-, dakiena, ez-ez. Ta... lenao? bai, lenaoko familiak, bat, oañik ere emenköa... familia dela (...), beña orai eztakite... uskera ere, ez-ez-ez.

\section{Gurasoez eta euskararen erabilera urriaz (1986)}

- Zure aitatamak nor ziren?

Nere aitetamak? ama Setoaingoa ze, beño ba!... uskera? erdera miño obeki zakie.

- Nola zuen izena?

Micaela, Micaela Santësteban; ta aite? Larraingoköa, valle de Erro, Larraingokoa. Arek ere... uskera, erdera biño obeki zakie, bai. Biek beti... uskeraz, mintze-mintzen tzire, beño gurekin? aek uskera? ta gu, gu erderaz (barrez). 
- Bai, e? zuek erdaraz erantzun, kontestatu...

Beño nik? e... guti; artzai arrekin, gizon arrekin, ikesi nuen pixket.

- Juanito horren aitarekin.

Bai, bai, Juanitoin ait(t)aikin; beño bestelaz? ez nue nik mintzetzen batre uskera, batre.

- Harekin bakarrik...

Bai, arrekin bai, arrekin beti uskeraz; bi urte ero ola... eon nitze ni artzai arrekin, ta ¡madre mía! ikasi nue (...).

- Bi urte bakarrik?

Bai, ta gero torri... gera, bertze erri batera, onara, Uarte ondora? ta emen, batre! ezta, ezte... erdera iten ja e, (zuzenduz): uskeraz batre emen...

- Eta, noiz arte, zenbat urte izan arte, mintzatu zara euskaraz?

A! ama-, amabi-amiru urte; yago ez.

- Hara bitartean euskaraz mintzatzen zinen eta geroztik jada ez duzu egin...

Ez-ez-ez-ez; orduen ere, ni, erderaz (...), beño, gizon arrekin? bai, beti, erderaz (!), beño...

- $\mathrm{Ba}$, oraino, aski ongi oroitzen zara...

$\mathrm{Ba}$ ! poco, poco, poco; ando muy penando yo pa hablar el vasco, muy penando.

- Tira, baina defendatzen zara...

Sí! no-no, no puedo.

\section{Ardiekin ibilia (1986)}

- Noiz hasi zinen ardiekin ibiltzen? zenbat urtetan?

A! nik? pues e, ardiekin? amar urte... ed'ola.

- 'Navarzalico' gisa? horrela erraten da?

Bai, ardiek? etxeköak, bai, ta... bertze etxe bateköak? ere... ibiltzen tzien, beita. Ta... gizon, gizon arek, Miguel Esain? arrek, Beztan etxekoak, zuen ardiek, berak, bäi.

- Eta, nondik ibiltzen zineten, nondik nora, ardiekin eta?

A! pues...

- Ea, konta ezazu egun batez zer egiten zenuten; etxetik zein ordutan atera eta nora joaten zineten, bazkaria edo ahamenen bat eramaten zenuten eta...

Ez-ez, zorroan, zorroan amen.

- Baina, ea, ze ordutan jaiki eta...?

E! yaiki? pues, eztait! zortzietan edo ola? ta gero...

- Herrian lo egiten zenuten? etxean?

Etxean, etxean, etxean... etxean; te geo... ardiekin etxera, lotara. Ta dermioa? iten tzuen muga... Setuaingoa, ta Ilerrazköa, ta... Erreaköa, ta Zaiköa. Ta... eun batez fa-, juaten dire Setuaingo aldera, bertze egun bätez... Erreako aldera, ta... ola, ta bertze aldi batez, Zai, Zaiko aldera, ta ala.

- Bazkaria eramaten zenuten?

Ez-ez; bai! guk ematen ginuen zorroan, arrazio pixket ta... ogi pusk'et aundie? ta e... eun, eun guziko.

- Ahamen bat edo, bakarrik...

Bai, bai, ta gero, arratsean? afal-, afaldu etxe, etxean berdin.

- Eta bazkaldu, non bazkaltzen zenuten? 
$\mathrm{Ba}$ ! segun.

- Arbole baten ondoan, itzaletan edo? bero egiten zuelarik...

Bero eiten duelaik? orduen, ejeje! orduen bai, ta bero aundie itten duelaik? iten tzuelaik? ardiek sartzen dire... ¿cómo dices tú 'en la sombra'?

- Itzaletan.

Bai, ta orduän, tortzen gine etxera... bazkaltzera, ta... atsaldean, lauetan o bostetan, refreskatu pixkät itten duelaik, orduen atratzen dire ardiek, bertzelaz eztire atratzen andik; ta faten gine... bortzetako ero ola? berriz ardien... ardiera; ta orduen atratzen tziren moskeratik? ta, yatera.

- Eta ardiak, horrela, itzaletara biltzen direlarik... horri nola erraten zaio?

E... en vasco no sé; en castellano 'mosquera', se llamaba, mosquera. Era un sitio, denak ezpelak, aundiek! ezpel aundiek ta... lurrian? garbi-garbie, dena, etze belarrik eta ja ere, ta ezpel aundiek. Ta an, agustue... an, gustora egoten tzire an ardiek.

- Gu bizi garen inguruan, abaroan daudela erraten da.

Bai, izen deike, bai, bai emen ere erraten da abaroa, bai.

- Aditu duzu, e? 'Ardiak abaroan daude'?

Abaroa, abaroan daude, bai. Beño... ez! an bertze izen bat badu, eztait nola erraten tzioten... itzelera o... eztait nola erraten tzen, bezte izen bat pa-, bazue an, bai.

- Beharbada gero oroituko zara.

Eztakit, eztakit.

- Eta, gero, bazkaldu ondoren, siesta pixka bat edo?

Ee! ba! zenbait aldiz bai, beño...

- Zu ttipia baitzinen igual ez, baina zurekin zegoen gizonak bai, eginen zuen pixkat...

A! bai, gizon arek bai, arrek bai, arrek... gustora ego-, egoten tziren arreki, bai. Ta... igendetan eta... aunitz aldiez? beak... idukitzen ardiek, denak, ta neri... uzten tzire, fateko... bertze... mutikoak? mutikoengana? ta...

- Fiesta ematen zizun, e? jai edo...

Bai, bai, bai, bai.

- Eta, bazkalorduan, zer edaten zenuen?

A! ni ardo pixket ta gizon arrek, etzue... ardoa... ematen; urä; nik ema-, maten nion, ardo pixkät, bai.

- Baina, zu sobera gazte zinen orduan ardoa edateko, ez?

$\mathrm{Ba}$ ! gutti edaten nue, pixk-pixk-pixkuat, guti.

- Non eramaten zenuen ardoa?

¿Cómo se le dice a la botella?

- Botilla.

Bueno, pues, botilla batëan.

- Zatorik ez zenuen? zatoa badakizu zer den?

Ëtxean bai, ëtxean baginezake beño ni, nik botella tzar batian, maten nuen, beti.

- Eta, gero, ze ordutan itzultzen zineten?

Ze, etxera? a! ilune... tiretu edo ola, iluntzera...

- (...)

Bai, bai, ala da; ta... ardiek, itzelera faten... zirenak? orduen, goizian atratzen ginduen goizao, yateko, freskure... dela're, denbora freskua...

- Zegoelarik? 
Bai, beroa... etortzen denean? ya yanik, ardiek irabazi, pero bestelaz, otz, denbora otza... Idragin ${ }^{10}$, inde buelta orra? orduen... ñe! atratzen ginue ardiek... beantago.

- A, berantago.

Beantago, bai; beño... urden? goizego atratzen ginuen.

- Eta, menditik itzulita, non gordetzen zenituzten ardiak? ardiek non pasatzen zuten gaua?

Gaua? etxean!

- Baina, etxeko zein lekutan?

A! pues guk bagindue... etxe ondoan, borda... zar bat? aundie? ta an. Guriak an, ta... gizon... arrek, ardien, gizon arrenak? etxean berean, bazute... beittien, pusk'et, ardiendako.

- Eta, han sarturik zeudelarik, han berean ematen zitzaien jana?

E-e neguen bai, neguen bai.

- Zer ematen zaie?

Pues... ostoa erraten tzaëgon ${ }^{11}$, aritzek eta... a los chopos ¿cómo se les llama en vasco? - Tzipue?

Tzipue; osto arrek... ebaki? te, paratzen ginuen paxu et, ta etxera ematen ginduen? ta, gero... paatu, ola, tzilintzen? emen bat, an beste at, an bestze at, an bestze at... korrale guzien, (...), ta, gero, zalkëa... pentsuteko zalkëa, oloa, ta... gariz e, zenbait aldi gari? gari gutti. Eta... gero, zalkëa?... a la veza ¿cómo se llama a...? al grano que se hace, o a la... a la malkarra que llamamos, a aquello no sé cómo le llamaban en vasco (!); eso también les dábamos a las ovejas. Y llevaban los corderos, cuando se criaban, en invierno siempre.

- Eta erue edo yerue, ez?

Bai, erure, erure bai... bai-bai, erue ere bai, maten diogu uk.

- Eta belarra?

Belarra? guk maten ginuen belarra ere bai.

- Hori, gehienbat, oihanean eta mendian, ez?

Beño etxean ere ematen giñuen belarra, bai; belarra ematen ginuen? ardiek, umiek, umekin da...

- Hazten zituztelarik?

Bai, orduen maten giñuen belarra, bai, belarra ta... pentsue ere... yago, zalkea ta erue ta... oloa ta... denetaik, maten giñuen.

- Eta, badituzte leku berezi batzuk ere jateko; horiek nola dute izena?

Pentsue yaten dutelaik? ganbela, ta... malkarra ta... ori? emen ganbelak? ta emen gañean, ola... matxadera erraten giñun, ta an botatzen giñuen, ba... belarra. Ta... zalkeaen ostoa? ure? e... ganbelan, bai.

- Gero, jetzi ere egiten zenuten?

$\mathrm{Ze}$, ardiek?

- Bai.

Gutti, zenbat... zenbait baño gutti.

10 Iragi izeneko herrixkan, antza.

11 '(Zit)zaion' dirudi horrek, berriemaileak, Yrizarrentzat galdekatu genuenean, zakio eman bazigun ere. 
- Zuk jetzi duzu?

Ez! nere amak... iten tzituen, beño gutti... ardiek e, eztire... klaseak, deitzitzeko. Deitzitzeko... latxak erraten tzuenek? orrek beste klase bat padire, burubeltzak eta... deitzeko oiek dire, beño gure ardiek ezt-, etzire onak deitzi-... titi ttikiek.

- Latxak ziren haiek?

Ez-ez-ez-ez-ez, ez latxak, ez, ez; (zuzenduz): latxak dire deizteko... oiek, bai.

- Eta, hauek ze klasetakoak ziren?

Marinak erraten tziote.

- 'Merinas' edo?

Marina; merinoak dire bertze klase bat, Kastillan o por ahi... izein dire, beño...

- Eta, hauek marinak?

Marina, marina, oek marina.

- Ez dira berdinak? ez dira gauza bera Kastillako merinak eta zuen hemengo...

Ez-ez-ez-ez; eztire... igual.

- Nik beti aditu dut hemen bazirela... marinak aditu dut Lintzoainen eta Agorretan eta...

Ez, aek... latxak die, Lintzoaingo ardiek? latxak, ta Agorretan? lenao ez, beño orai ere latxak, deiz-, deizteko, bai, beño ya, Agorretatik beitixeo? ya... dire...

- Marinak?

Marinak; marinak o churras o... klase ortaik. Ta emen ere badire churras, o marinak?

- Hortaz, marina eta txurra gauza bera dira?

Bai, nik uste baetz... bai-bai-bai, marina ta txurra bai, gauza bera.

- Inguru honetan erraten zaio 'marina' churrari, e?

Bai, bai, ori, ori, ori... ori de.

- Ba, nik, erraten dizut, 'marina' izena aditu diot Lintzoaingo gizon bati ere...

Bai?... lenao ezin dake; orai sorik denak latxak tire an e. Lenao? eztait, akaso... joe! izein dire, beste eztakit, bezte... txurrak o marinäk, beño orai latxak denak. Ta Agorretan ere? latxak orai; lenao ez, lenao... marinak, o churras, como les llamen. Ta ori.

\section{Gazta egiten ikusi bai (1986)}

- Lehengo egun batez erran zenuen zuk ez dituzula ardiak jetzi...

Ardiek? ez, ez. Nere amak bai, bai, nere amak bai, ardiek eta auntzek.

- Egiten zuen gaztarik?

Ez-ez, ez, ya etxeko, ya-ya yateko etxean.

- Eta, nora jezten zuen? nora ateratzen zuen esnea?

¿Cómo? eztait nola erraten den.

- Kaikura edo?

Ez, kaikure ez; kaikure...

- Pozalera edo?

Bezte... katxarro at, puchero o... olako at, olakoa zerbait.

- Eltze batera edo? 'eltze' erraten zitzaion?

Bai; an? Setuañen? kaiku... kaikure, Setuañen, beño Ezkirotzen... eltze batera edo ola, bai.

- Baina, gazta askorik ez zuen egiten... 
Ez-ez, ez. Bai! zenbait itten tzue, bai, bee-, beekin... beaekin zenbait aldiz? ezne, beako esneaki? iten tzuen zenbait alditan, gazta bat o...

- Oroitzen zara nola egiten zuen?

Ez, paatzen tzen, eltzea... beteik? ta gero, botatzen tzion kuajoa edo ola? ematen tzuelaik?

- 'Gatzagia' edo?

Bai.

- Bai? hala erraten zaio?

Nik uste bai.

- Eta, gero, zer egin behar zen?

Gero? eztakit... idukitzen tzuen... aunitz denbora? etxean? ta gero, asten tze, paatzen tze kuajo bezala, ta artzen tzue? ure? eltzetik? eta, iñalak in, ederki ertsi-ertsiturik dena... sueroa erraten tzenuen? ure kendu...

- Gazura edo? 'sueroa'?

Bai, sueroa.

- Erraten zitzaion 'gazura'?

Sueroa! sueroa; bai, eztakit, eztakit, akaso... 'suero' erderaz, akaso erraten tzen oe, bezte... Ta gero eztagit, baze, katxarro at? an paatzen tzuen? ta ertsi-ertsi-ertsi-ertsie? ta gero buelta at? ta buelta ta buelta? ta... an, inik geiltzen tzen.

- Egin arte.

Enaiz oroitzen... seguro, beño ola iten tzuen.

- Eta, gero, idortzeko, non paratzen zen?

A! pues, an, leioan edo... leioan ere bai, ta gero... sukeldian? bai, irukitzen tze, ta despensan ero ola, zenbait armario gañan edo ola...

- Eta, egon behar zuten leku hotzean ala beroan?

Eztait, leku beroan? nik uste... otzan nik uste, obeki, bai, nik uste otza.

\section{Inguruko balizko euskaldunez (1986)}

- Errean euskaldunen bat ezagutzen duzu?

Errean ere, uskera, orai... ezta izein. Bai, akaso... akaso mazteki bet bada, bai, an... urte aunitz an...

- Zein, Txokorenekoa?

Ez, Paulorenaköa.

- Zein izen du?

Izena nik eztakit, badaki... mi cuñada ya sabe, sí.

- Ez da izanen Josefa Esain...

Ez, ori emen dago, Josefa Esain.

- Bai, Antsoainen; horrek guti daki.

Bai, akaso arrek ere...

- Ez-ez-ez; ez du egiten zuk bezala.

Ez? ba, pues akaso arrek ere eztaki aunitz, nik eztait, orai Errean dagona. Zerbait akaso badaki oi, eztakit.

- Eta, Akerretako Jose Esnoz, ezagutzen duzu?

Bai, urte aundiz e bai, (...).

- Laurogeita sei edo... 
Ba, bai; bizi de? zautzen dut, bai.

- Horrek euskara daki?

Eztakit, izen daikën; akaso, eztakit.

- Nik uste dut zerbait badakiela, baina...

Bere aitek? bai, bazakie, pero orai? berak akaso? aite... t'aiteikin, akaso zerbait? eztait, izen daike zerbait badakien, eztakit. Jose zaio, e?

- Bai.

Bai-bai, berdin. Urte aunitz tu orrek.

- Zuriaindik hurbil bada baserri bat: Gendulain...

Bai, Gendulain, bai, bai.

- Inor bada hor oraindik? jendea bizi da hor?

Eztakit orai bizi ote den, lenao bai, lenao bi familie sorik bizi ziren.

- Euskaldunen bat bazen hor lehen, adin handiko emazteki bat bederen ${ }^{12} .$.

Eztagit or, in dute... guti; akaso bazakite biño eztakit beño, erdera geiao... iten tze.

- Eta, Zuriainen izanen ote da euskaraz mintzo den norbait?

Eztagit, akaso? izein tze orduen norbait, beño... gero, berritz, orai ka!... orai nik uste, an, iñor ez, euskera...

- Ez da izanen.

Ez, ya ez.

- Izan naiz orain Ilarratzen, Tomas Arregirekin...

Aaa! arrek badaki uskera.

- Erraten du ezetz.

Ezetz? Erreako semea da ori, ta... bere aitetamak euskaldunak, zire.

- Erran du aitak bai, baina ama herrikoa zela eta gutxi zekiela. Eta aditu dut ere Erreako beste emazteki bat, Francisca Eugi, Arrietan bizi dena...

Bai, badakit.

- Eta, zer uste duzu? jakinen ote du euskara?

Eztagit, aittetamak badakizu, e...

- Bazekiten?

Bazakiten, bere amak; bera? eztakit, nik; aitetamak? euskera?... erdera beño obeki, bai-bai. Orai eztakit, t'etxean, aski iardukitzen... uskeraz? eztakit, beño, aitetamak bai. Arrek? izein tu orai... iruetanogeita amasei o amazazpi izein tu.

- Aspaldi dago han?

Bai, ezkondu ze arara, arara, Arrietara.

- Orduan, denbora aunitz du han dela...

Bai, bai, bai, aunitz, igual berrogeita amar urte (...), Arrietan ere. Nik e, zautzen nue orduen, etxean zegolaik, beño orai? enue zautuko.

- Eta, bertzenaz, euskara dakien bertze inor ez duzu ezagutzen?

Ez, Erreaköak? je! errateunte eztakitela! orai... lenaokoak il tzire denak? ta oraikoak? pues, ni eztagit.

12 Saio honen hasieran aipatu dugun Juana Irure anderea, Inbuluzketako berriemaile Apolinaria Egozkueren amaginarrebakidea zena. 


\section{Sanjuanetako ohiturak (1986)}

- San Juan bezperan sua egiten da?

Bai, ori bai, orai ere iten due emen; emen ere ite-, iteunte, orai, orai bai. An... erri guzietan, iten tze, San Juan bezpera, bai-bai.

- Nola egiten zenuten? bildu eta...

A! pues, bildu... abarrak eta, jeee! itxean, etxeko atarien, denek baginduen abarrak eta...

- Egur zenbait eta...

Egur-egur zenbait te ola? ta, an biltzen ginuen, denetaik? ta, erdi-erdien edo ola, leku bät... paratzen ginduen? ta, ala! ta sa-, saltoa! arata, salto onata! salto arata ta, erraten ginuen, salto in genduena? 'sarna fuera!'. Ori erraten gindue.

- Hori bertzerik ez?

Ez, enaiz oroitzen, eztagit.

- 'Kaiku eta ganbela pera' edo, ez?

Enaiz oroitzen ni gortaik.

- Eta, apezak zerbait bedeinkatzen zuen?

Bedeikatue? iten ginduen... gurutze batzuk, nola erraten ginuen? 'ramos' erraten tzen, ta pa-, maten ginuen? elizera, ola, paxuak. Ogei odo... berrogei eo seun, paratzen ginuen? pakete batëan? ta elizera, ematen ginuen, ta... gero, apezak? beredikatuä... in? te gero, paatzen ginduen? alor guzietan; alor batean? kruze bat, ta bertze alor batean? bertze kruze bat, alor guzietan paratzen ginduen gurutze artaik, kruze artatik; ramoak, erraten gindue.

- Orduan, zenbait alor iduki, hainbat gurutze bedeinkatu...

Bai, bai, bai.

- Eta, gero, alor bakoitzak berea...

Ori, ori... bai, bai, bai. Orai... nik uste ezten, ezten iten orai, beño, ni... Eskirotzen nindebilelaik? bai.

\section{Animaliez oro har: 1) Basapiztiez zerbait (1986)}

- Alimañak eta horrelako animalia txikiak ibiltzen ziren? azkonak edo azkonarroak eta...

Azkonarroak zer, ze bitxo dire?

- Azkona da 'tejón, tajudo' eta...

A, bai, bai.

- Harrapatzen zenituzten, zepoekin eta?

E! nik ez. Bai! zenbaitek arrapatzen tzuen; nik ez, eee! eztut, nere afizioneik ni.

- Zer-nolako animaliak ziren haiek?

Pues, tajudoa ta, gero... al zorro ¿cómo le llaman, en vasco?

- Axeria?

Axerie.

- Eta basagatua?

Bai, basagatuä bai, bai; basagatoa... zenbait, arrapatzen tzuten, basagatöa, biño eskopetaikin ero... eztait.

- Zepoekin eta, ez?

Zepoaikin? akaso zen-, ere bai, eztakit. 
- Eta, arboletan ere beste batzuk izaten ziren, ez?

Arboletan? eztakit.

- 'Ardilla' eta 'lirón' eta horiek, ez?

Ardillak eta badire bertze batzuk, mixarrak o eztakit nola erraten tzaion?... iteunten zulö at, iten-iten tzuen... arbolean? ta an, umeak gan, azten tziren.

- Haiek ere harrapatzen ziren?

Baite, baite.

- Eta, nola?

A! aise... eskueikin.

- Ez zuten koxkarik edo egiten?

Ez; nik enue arrapatu beiñ ere, beño arrapatu tuzte.

- Onak dira jateko?

Bai, yateko bai; eztait onak tziren, beño yaten tzen, yaten tzen.

- Aditu dut beren urina ona dena larruaren gaitzak, erreuma eta, sendatzeko.

Eztakit, bai, nik uste erraten tzen erreumaindeko ta... ona dela aren... uriñe edo, bai-bai.

- Eta, 'ardillari' nola zaio euskaraz?

Izen daike burtzintze ere, beño enaiz...

- Izan daiteke, e?

Izen daike burtzintze, bai, izen daike burtzintze ere.

\section{Animaliez oro har: 2) Hegazti harrapakari batzuen aipamena (1986)}

- Zuk badakizu zer diren zapelatzak, arranoak eta gisako harrapatxoriak?

Bai, arranoak badakit nik nola zabiltze.

- Bai? ikusi dituzu? han ibiltzen ziren?

Bai, bai, Eskiro(t)ze-, Eskirotzen ere aunitz aldi, ta, ematen tzuen, txitak o eztakit nola erraten tzen, artu te...

- Bai? arranoek ala txikiagoko bertze horiek? zapelatzek eta...

Bai, nola erraten nion ai?

- 'Galforroak' edo...

Kalforroak! bai, kalforroak; oek? oik gaixtoagoak dire oaño, bai, beño arranoak ere? ta... faten tziren, bai.

- Baina, etxekoek ez zituzten nolanahi utziko...

Bai, beño, juaten ${ }^{13}$ tzire pixket ta, aparte.

- Eta, deskuidoan...

Bai, bai; ta... etxe, etxe ondoan ere zenbait aldiz sartzen tziren. Gu, guk, or bagindue etxeetik segidoan Agorretan... nola erraten duen? a la era ¿cómo le dicen?

- Larraina?

Larrañe ondoan? pixke bat? ta an, ibiltzen tziren gure olloak eta... loka ber txiteki, ta an, franko aldiz, andik ematen tzuen; pues kasi, kasi etxe ondotik.

13 'Fan' eta 'juan' aldaerak erabili zituen berriemaileak elkarrizketetan zehar, aurrenekoa askoz ere gehiagotan, halere, bigarrena baino. 


\section{Animaliez oro har: 3) Narrasti batzuen aipamena (1986)}

- Sugeak eta baziren?

A! bai, oiek bazire kulebrak, bai.

- Badira gaixtoak eta hain gaixtoak ez direnak, ezta?

E! nik eztait, eztut zautzen zein den gaixtoa eta zein den... bazire kulebra atzuk tta-

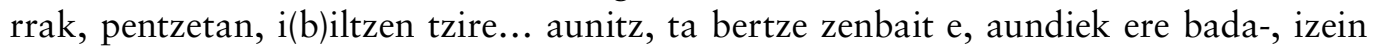
tzire, zenbait peño, geiao? oetaik, pentze... pentze oëetako olaxe-, olakoak edo.

- Ze kolore zuten? berdexka edo?

Berdexka?...

- Edo grisa edo?

Grise yago, berdexka beño. Berdeak? izein tzire aundi oetaik; oiek bai berde, berde, berdea, berdeak.

- Eta, gaixtoenak zein ziren? eztakizu...

Eztakit, eztakit.

- Baina, benenorik eta, aunitz ez; zuk ez duzu ezagutzen horren hozkatik hil den inor, ezta?

Ez, il ez, beño nesako at? an, Agorretan? eon tze... eri-eria karri zioten. Bai, suge bat, piketu ziola? ta, aunitz inflamatu zen? ta, Iruñean egon tze, beño, eztakit lau edo bortz egunez, bertzerik yaus! bertzeik eztut zautu nik.

- Eta, muskerrak eta halakoak izaten dira?

¿Muxkerra qué es?

- 'Lagarto'.

A! bai, kusi tut nik lagartoak orduän. Lagartoak? emen, Ezkirotzen, geiao, Agorretan baño.

- Bai?

Bai, nik artzain nabillela? ibiltzen nitzelaik? kusi nuen bai.

- Idorragoa da lurra, ezta?

Eztakit, idorragoakoa den.

- Akaso horregatik?

Izen daike, izen däike.

\section{Ibaiko arrantzaz zerbait (1986)}

- Arrainik harrapatzen zenuten? edo amuarraiak edo, nola erraten duzue 'trucha'?

A! ämorraiak, amorraiak.

- Harrapatzen zenuten?

Ez, nik ez.

- Bertze batzuek bai?

Bai, pues bertzeak? ta... an, Agorretan, bazire, arrapatzen tzuena.

- Eta, badakizu nola harrapatzen zituzten?

Pues... eztakit nola erraten den uskeraz, 'vara' erraten ginion... erderaz; bara, ta gero... antzueloa paatzen tzioten...

- Amua?

Eztait nola erraten, nola erraten den, ta arrekin artzen tzute.

- Eta, 'vara' hori zer da? kañabera? la caña? 
Bai, caña, caña. Ta eskuekin e artzen tzute zenbait.

- Prohibiturik zegoen?

Bai, proibitui tzeo? beño artzen tzuten, eskuz, eskue-, eskueiki. Sartzen tzire... zubire? ta, zubiek, nola tira? 'el río'?

- Uhaldea?

Ugeldea! sartzen tziren ugeldean? ta, erri, erri... pean? ba, sartu zen? oñez!

- Harripean?

Bai-bai-bai, arripean, bai-bai.

- Eta, aise harrapatzen ziren?

Bai, bai, bai; nik ez, beiñ e, beiñ ere.

- Eta, bertze batzuek erabiltzen zituzten retelak edo...

Bait'ere! bai, zareak ere bai.

- Sareak eta.

Bai, paatzeungu...

- Eta, guardiaren bat ibiltzen zen?

Bai-bai, bai.

- Multa eta, paratzeko eta?

Bai, beño? faten tzielaik... orduen, faten tzire... bat ero bide edo ola... ugeldera? ta bertzeak bijiletu.

- Ea guardia heltzen zen, eta horrela bazen desaparezitu, ezta?

Klaro! ajajaja!...

\section{Ferragintza Zubirin (1986)}

- Eramaten ziren abereak ferratzera?

Zer, abreak?

- Bai; nora eramaten?

Zubiri, Zubrire.

- Zuk eraman dituzu?

Bai.

- Orduan badakizu nola ferratzen den...

Bai-bai-bai, badakit. Mandoak eta idiek ere bai.

- Ba, kontatu, kontatu ongi...

Ematen ginue ferratzera? ta...

- Zer, behiak edo mandoak edo astoak edo?

Biorrak, guk biorrak gindue.

- Behorrak, e?

Bai, guk bai, ta, besteak, mandoak, denetaik, juaten tzire(n). Nik? biorra eman nuen ta, ba, eztakit. Pues paatzen tze... bea? ferratzen... ai zelaik? ta nik, artu anka... biorraiñak? aurreri ona? ta nik atatzen nuen anka onara; gero... emen? paratzen...

- Zure zangoaren gainean?

Bai, ta arrapatu ola? ta patzen ginuen azazkala, berak... aitzeko, ta an, bazen katxarro at, ola iteko? ta gero...

- Nola zuen izena? 'pujamante' edo horrelako zerbait?

Bai, pujamante, pujamante erraten tze.

- Eta, harekin zer egiten zen? 
Pues... kentzen tzio, azazkalai... puske batzuk, paratzen tzuen, ongi, gero... 'herradura' erraten tzëon ${ }^{14}$ ¿cómo en vasco?

- Ferra, ferra.

Ferra, preparatzen tzuen ferra? ta paratzen tzion azazkalan? ta gero, ferra orrek bazue, ola... ¿cómo se dice 'pa los aujeros'?

- Zulo zenbait?

Zilo zenbait? ta an sartzen tzion, itzeak? ta pasten tzion bertze aldera, itzekoa? ta, gero? punte... sartzen delaik bertze aldera? moztu, punte berä, tenaza atekin? moztu; iru... itze? ero, batian eta bertze aldëan? bertze iru, ta... gero, puske at an ere moztu? te, paratuik... bai.

- Mina egiten zitzaion?

Ez-ez, miñä ez.

- Horrekin hobeki ibiliko zen...

Bai, orduen... pues, etze... ibiltze de an haunitz ${ }^{15}$, beño... burdiñe? ba, burdiñe du ori, ferrea, ta, arrekin... ederki...

- Zapatak balira bezala...

Igual-iguala, igual-igual.

- Eta, ferra paratzen ez bazen, zer gertatzen zen?

Azazkala... gastatzen tze ta, ta autsi te eraiten tze. Beño ori, iten tze? por ejemplo... bior bat, lanean ezpada aitzen? eztu... faltatzen, ez, beño lanëan aritzen bada aunitz? orduen, orduen bai, ferreak paratzen tze, bestelaz, kanpoan dabiltze... yaten edo ola? ta... ezpadire lanian aitzen ez.

- Eta, ferrak paratzen diren lekuak zein izen du? ferratzeko lekuak?

A, lekue? ez.

- Ez du izen bereziren bat edo?

Eeztu, ez, eztu; gan, lotu... biorra... emen? ta...

- Uhal batzuekin edo?

Bat ja, bat ja ere, ez; idiek bai, idiek... idiek paatzen tziren... 'potro' erraten tzeon.

- Potro?

Bai, potro; ta, an sartu? te... maroma batzökin? goittitu, ta gero, goiti paratzen tzirelaik? emen, zango at? emen bertz(e) bat? ta... atzenekoak ere igual? olatxe paratzen tzioten? ta... orduen idie an, etzaike... moitu. Ta an iten tzioten gero... gastatu azazkala? ta paatu bera.

- Bai, besteari bezala, e?

Bai, ta... ferrak paatu? te gero, berritz, beiti... soltatu? ta bereriz e... lurrera? ta, atai, atai.

- Paratzen ziren ez maingutzeko, ezta?

Bai.

- Eta, zergatik sujetatzen ziren horrela behiak, eta ez mandoa edo behorra?

A!... beak ez, eztai-, eztaike... iduki ola.

- Ez? zergatik?

Brr! indarr aundiäk du e... zanguetan beak.

14 Geroxeago ere 'zeon' bat aurkituko dugu, batak zein besteak, zein testuingurutan dauden ikusirik, 'zitzaion' ('hura hari', irag., singularra) diruditena. Lehenago ere antzeko kasuren batekin topatu gara.

$15 H$ hasperendua aditzen uste dugu hor, egundoko salbuespena bada ere. 
- Bai? mandoak baino gehiago?

Bai, bai, idukitzeko bai, irukitzeko bai. Mandoak, nik eztagit, akaso... geldi-geldiek egoten tziren kasi, pixket, mobimiento zerbait iten tzuen? beño gutti, gut(t)i; egon tzire... geldirik.

\section{Gaztetan Eguesibarko Altzuzan bizi izanikoa (1986)}

- Joan izan zara herritik Iruñeraino ganaduarekin edo?

Ez.

- Eta, bertzenaz, oinez edo? sanferminetan edo zerbait ekartzera edo?

Bai, beño... ni Iruñera fan nitzelaik? fan nitzen, igual... eztakit beño igual amazazpi urte (...), eztait, amasei o amazazpi urte.

- Eta, joan, nondik joan zinen?

Altzuzetik, Altzuza, or, Uerte ondoan, or. Or, an egon ginen... amabortz urte(z).

- Altzuzan?

Bai; ta gero, ordik? fan gine berritz? Agorretara... valle Esteribar.

- Ardiekin eta?

Ez, ardiekin? ni, ardiekin ibili nitze... amar urtet-, bedratzi-amar urtetaik? amabi urtetaa, ero ola.

- Hiru urtez edo bakarrik.

Bai, bestelaz ez; ardiek bagindue bai, etxean, beño artzaëa... erriko artzaëa ibiltzen tze, bai.

- Eta, ordura arte, zertan aritu zinen?

Pues, ardiekin kanpora... gintue.

- Etxeko ardiekin eta?

Bai, etxeko ardiekin? ta, bertze etxe o... etxe, etxekoak? ibiltzen nitun nik, bai.

- Eta, gero, bederatzi urteetarik hamabiak bitartean...

Pues orduen, nik amiru urte... bete gabe? torri ginen Altzuzera, ta orduen? kanpoan, lanean, lanean, idiekin tä... altzurreiki te... denetik.

- Han bizi izan zinen, Altzuzan...

Bai, amabortz urtez, amabortz urtez bai, ta gero ordik? fan ginen Agorretara berriz.

Ta Agorretan ere? ardiek baginue etxe-, etxean, beño... ni enitze ibiltzen, ez.

- Eta, Altzuzan bizi zinenean, zenbat famila ziren han orduan?

Ze, Alzuzen?... zenbat?

- Bai; sei? zortzi?

Zazpi, nik uste (y)a; una en Paularena? una en Bueno? Zaku tres, la Abadia cuatro, Otelo cinco... Lotero seis ${ }^{16} \ldots$

- Ez, gutiz goiti beiti.

Zazpi! artzaiekin zazpi.

16 Izen hauetakoren bat gaizki aditzen ote genuen beldur, saio hau FLVen esku utzi aurretik, 2017ko abenduan, Altzuzan izan gara zalantzak argitze aldera. Kontua, baina, korapilatu egin da, bertan bizi den Pedro Urrutia Armendarizek eman dizkigun izenak, 'La Abadía' kenduta, ez baitatoz bat berriemaile ezkiroztarrak aspaldi emanikoekin. Hona izenok: Adamerena, La Abadía, Jakuerena (euskara herritik desagertu ondotik, 'Casa Jakue' deitua), Bernardinorena (id., 'Casa Bernardino'), Zabalena, Lustarra (eroria) eta Ezkonberrirena (gaur egun, La Abadía-ri atxikirik, ahoztegi bihurtua). Arazoa, damurik, ez dugu argitzerik izan. 
- Eta, euskaldun bakarrak zuek, zure familia bakarrik.

Bai.

- Etxean egiten zenuten euskaraz?

Gutti! gutti, bat ez kasi; aitetamak!... aek, yakite iten tzue, uskeraz beño... gu bezik.

- Denbora haietan, gehien-gehiena Ezkirotzen egin zenuten, ezta?

Ezkirotze, Ezkirotzen, bai-bai, Ezkirotzen.

- Ttikitan, mutiko ttarretan eta horrela...

Bai, Ezkirotzen, beño.... ya emen, Alzuzen... batre.

- Orduan herritik Iruñera ez zara oinez etorri...

Ni ez, Ezkioztik?... Altzuzetik bai, beño Alzuzetik? Alzuzatik oñez ez, Ugerteraño, Ugertean a... artzen biginduen, tranbia erraten tzen, orduan tranbia ze ara, Ugärtetik Iruñea. Orai, autobuse pezala? ordun, tranbia. Ta oñez? Alzuzetik ez, Iruñetik Alzuzera bai, oñez (barrez), sanferminten.

- Zein herritatik pasatzen zen?

Pues... Burlada? Billaba? ta Uarte, iru, iru daude, iru dire.

- Nola erraten duzue gehiago? Billaba edo Billeba?

Billeba nik uste.

\section{Ezkiroztik Iruñera zein Setoain aldera (1986)}

- Ezkiroztik Iruñera oinez etortzeko, nondik pasa behar da?

Bai, bai; pues pasa bear du...

- Lehenbizi?

Lemizik? Larrasoaña, o Urdeizti, segun, biak eta izan, fan tzaike, ta gero, andik... Zuriaña, Zuriain; Zuriañetik? Antxoriz, ta gero...

- Antxoriztik...

Zabaldikera, ta Zabaldiketik? Uertera ya. Ugarte, Billeba, ta Burlada ta Iruñera.

- Zenbat denbora behar da handik hona etortzeko? lau ordu edo?

Bai, ola, lau orduetan... torri deike, bai, ongi lau orduz. Ba, gazte bat, ola!... aitona ya... beño gazte bat, lau orduen... ongi etorriar du.

- Eta, artzai harekin ardi zaintzen ibili zinenean, zein aldetara joaten zineten?

Nundik? pues Eskiozko... Ezkioztik? Setoain aldera, ta han ${ }^{17}$ iten mugä, Setoaingoeki, ta gero... beste aldera, Ilarrazkoeki(n), mugatzen duen... Ta gero, Zaikoekin ere mugatzen tzuen, ta Erreakin ere bai, ta or, lau erri oetan? mugetzen tzen... Ezkiozko dermioa. Ta or ibiltzen gine, egun betez Setoain aldera? bertze egun betez Ilarrazko aldera, ta bertze egun betez... Zai aldera, bertze egunez e... Errea aldera, ta ola, ibiltzen gu beti.

\section{Kinkaileruez zerbait (1986)}

- Kinkaileruak nondik agertzen ziren?

Ba! kinkalleruak... faten tzire... Ugärtetik? eta... gero berritz, Bizkarretetik? a ver... a ver telak berritz, saltzeko.

$17 H$ hasperendua aditzen uste dugu hemen ere, balizko 'gan' bat baino gehiago. 
- Ehunak? oihalak edo?

Bai, ta Uerteko ori?... ¿cómo se le dice a la uva?

- Mahatsa?

Matsa, ta tomatea ta pimientue ta... denetaik maten tzuen, etxeaz etxe ibiltzen tze.

- Orduan, saltzaile ziren, ez kinkaileru bakarrik.

Kinkalleroa zer da?

- Ba, hainbeste gauza saldu eta konpontzen ibiltzen direnak: eltze, plater, paraguas...

Ya-ya-ya-ya, bai, or, oetaik ere bazituzten'tzu ere bai; ibiltzen tze bat... Lunbierkoa. Lunbierkoa? ibili da bat e, eltze, eltze ta... oetaik saltzen tzue; eltzeak eta... platok ta oetaik.

- Bai, denbora batez Ilunberrin, Lunbierren, zeramistak baziren.

Ta Billeban ere bazire. Billeban, ta... ezta aunitz urte oañik (...), Billeban, iten zute, auniz klase...

- Bustinez eta?

Ba, bustiñeki, bai, auniz klase katxarroak iten tzuten, bai, Billeban.

- Ontziak eta bertzak eta...

Bai, bai, bai, denetik.

- Pitxarroak eta...

Bai, bai, bai-bai, iten tzute(n).

- Eta, Billabako hura orain non da?

Orai? eztait bizi diren... akaso ezte biziak... iñor ere aetaik.

- Eta, herriko zein lekutan edo zein karriketan zegoen?

Billeban? pues... erri erditik, karretera...

- Trinidadeko ermitara jotzen duen horretatik?

Bai! te Trinidadeko... pixket lenao, Trinidade... elleatu? e bederatzi... an iten tzuten.

- Eta, zein izen zuen? oroitzen zara?

Izena? 'el ollero' erraten tzioten denok, 'el ollero' erraten tzioten denok.

- Hori Billaban berean, e?

Bai, bai, bai; 'el ollero' erraten tzaio... nik uste, zartu ertio iten tzuen, bai-bai.

- Eta, hari erosten zenioten?

Bai-bai, ta ibiltzen tze... erritik e, erri guzietan, saltzen, ibiltzen tze.

\section{Lur langintzaz zerbait (1987)}

- Erekitzeko, zer egin behar zen? lehenik lurra behar zen altxatu, ezta?

Bai baño leenik? arrotu lurre!

- Zerekin?

Pues... zerekin? brabaneki; braban... makina, braban ${ }^{18}$ erraten diote, braban, ta bi idi pare... paatzen tziren? arrotzeko? ta gero, berritz, lurre... igualatzeko ta... eso de? area erraten tzioten, bai. Ta gero, ure ereki?...

- Brabanak badu bertze izenik?

Ez, nik uste t'ez, ez. 
- Eta, lehenagoko goldea edo kutrea edo?...

A! bai, ori lenaoköa ze, bai; kolde ta kutre bai, badire bai, bazire nere denboran. Erekitzeko garie? koldeaiki; oi ya da... katxarro bat, nola erraten da, pues?... punta bat onara da berriz? ta, gero, timona erraten tzioten? ta bi bearriek, be! ola, bi oetaik? ta... puztena emendik agarratzeko? ta, arrekin erekitzen tze(n) garie. Beño lurre da... arrotuik, ure lenagotik, bra(b)anaiki, ta gero arrek e, gariä? koldeiki.

Ta kutrea, berriz? kutrea, ori zen... uden, kosetxa kentzen... delaik? arrekin arrotzen tze t'an... zerbait, lurrëa; arrotze ta ba, gurrin ${ }^{19}$, gurrin bät, ola, sartzeko lurrean? ta, gero timona, erraten tziote? idiek an, paratu? te, tirätzen tzute, ta, arrekin seguro; zalkea etzen lekuen, ta gero iten den lekuen, izein tze arreki, kutreaiki. Nik zautu tu(t) ori're, biño... ya, gero berritz... etze ibiltzen bate, ya. Brabana erraten tziote, arrekin arrotzen tzute dena.

- Nola erraten zenuten, kolde edo golde?

Ba! eztakit; zenbait golde? bertzek kolde? eztakit nola ze.

- Zuek nola, normalean?

Kolde; kolde, bai.

- Timona ere aipatu duzu; horrek bazuen beste izenik?

Ez, nik uste; espera... eztagit, eztakit, akaso bazue, akaso izein tzue bezte... bezte izena, eztait.

- Eta, zalkea nolakoa da?

Zalkea? 'veza'. Granoa beltx bat, beltza da, granoa.

- Hori animaliendako da, ezta?

Bai, bai-bai-bai; ardiendako ta gorki ona... granoa? ta... ostoa ere bai, malkarra gelditzen tzen (...) ardiendako. Biño orai ezta erekitzen batre; orai, gari pixket? eta... 'cebada', garagarra, nola erraten tzen 'cebada'?

- Bai, hala da, hala.

Ori, klaro! akabo... ezta yagorik. Ta ogie emen, ya... gu, ni, naizen lekuen? an, batze, dena belarra, beiändako, ezta erekitzen kasi batre orai.

\section{Txori eta txorimaloez zerbait (1987)}

- Etortzen ziren txoriak hazia jatera?

Bai, bai, bai.

- Zein txori izaten zen hor, zein txori-klase?

A! pues e... nik eztakit nola erraten tzioten, tortzen tzire... txori betzuk, nola erraten tzioten? txui? txui? batzuk xuri eo ola? ta... puztena gorki, artzen duen gutzia? eztait nola erraten tzion xoriai, eztait nola erraten tzioten, beño... klase bat, juaten tziren, aunitz, garie yatera.

- 'Aguzanieves', edo?

Nik ori eztagit, eztait nola... erraten tzioten txoriari, ez.

- Baina, txori-klase bat baino gehiago etorriko zen, ezta? 
$\mathrm{Ba}$, eztagit, aek, klase bat? aunitz tortzen tzire; bertzeetaik? bai, tortzen tzire bertzeak ere bai.

- Zuek 'txori' erraten zenuten?

Lurtxorie ta...

- Lurtxorie? edo elurtxorie?

Eztagit, akaso elurtxorie da beñan, lurtxorie erraten giñion, akaso elurtxorie, bai.

- Eta, zein beste txori-klase ezagutzen duzu?

Ai! ni eztagit.

- Badira batzuk beltzak, ezta?

Bai, badire... nola du izena? kaguensos!

- Zozo?

Eztakit, ze-ze izen dun, akaso ala da, beño badu bere izena arrek, badu. Zozoa, akaso... zozoa da; eztait, eztait.

- Eta, bertze batzuk badira, 'malviz' erraten zaiena; horiek badute izena euskaraz?

Bai, badu, badu.

- Birigar-, biligar-...

Akaso biligarro izein de, bai, biligarro izein de; aunitz ibiltzen dire leku oietaik.

- Eta, badira ttiki batzuk, papoa gorrixka dutenak.

Bai, papogorrie erraten gindio oiei, papogorri.

- Eta, txoriak baratzeetatik uxatzeko, ez zen paratzen muñeko bat beztiturik edo?

A!... ez, ez, zegatik emen? idiek, paratzen tzire emen, erekitzeko, ta... idiek tortzen tziren bezala? botatzen gindue... azie.

- Eta, pikorra berehala tapatzen zen...

Tapatu, bai, segidoa tapatu dä ori, eta... bi ordu o iru ordu egoten balin tza, egoten bazara arara? pues, e! zenbait grano faltatzen tziren, beño ez aunitz, ez aunitz.

- Dena den, zenbait lekutan ikusten dira halako... erdaraz erraten da 'espantapájaros'.

A! bai, ori paatzen dire... Jesus! garietan ezt-, ezta ori paratzen.

- Ez? eta alorretan eta...

Be! alorretan gutti, geago paatzen tziren, badakizu zereki? zertaik? paatzen tziren... olloak, txitek bazutelaik? ta kanpora ateatzen dire aek? an, non ibiltzen den... oilloa... txitekin? an paratzen tze, nola, gizona bezala... eta biltzeko...

- A, igual zapelatzak eta...

Bai, bai, eta biltzeko aiek. Orietan? paratzen tzire... ez arrapatzeko txitek.

- Eta, euskaraz nola erraten zaio muñeko horri?

O! uskeraz?... 'espantapájaros'.

- Baina, hori erdara da.

Espantapájaros? A! bueno, erdera, bai, ori erdera da. Uskeraz, zein erran (...) onek?

- 'Txorimaloa' edo?

Ez, enaiz oritzen ni, nola... ze erraten tzioten, ze, nola.

\section{Zitu edo labore eta lekadunen ereintza eta bilketa (1987)}

Zure gazte denboran baziren ardantzeak zure herrian?

Gure errien? ez.

- Ez ardo, ez txakoli eta ez...

Ez-ez-ez, ez; lenao izen deike... 
- Izatea.

Izatea, zergatik badire zenbait kanpo errate tzaiona 'la viña', ta akaso lenao, izein tze biñe, beño nik eztut zautu.

- Eta, zure denboran, zer erekitzen zen?

Nere denboran? pues, garie, oloa, ta... a la cebada no sé cómo se le suele llamar...

- Garagarra?

Garagarra, neski, ta 'avena'...

- 'Avena' erran duzu: oloa.

A! oloa, ba-bai... ta zalkea, que es 'la veza'... ta, txitxirio pixket? banatö guziek, ola.

- Eta, erue edo yerue?

Bai, yerue ere bai.

- Hori zer da? erdaraz nola erraten da?

Erdaraz? pues 'girón', gerón, gerón; gerón o yero o eso, pensutäko da ori, pensutako, bai; ori ere erekitzen tze nere errien, biño... orai? orai ezta erekitzen.

- Eta, horiek noiz erekitzen dira? bakoitzak badu bere denbora, ezta?

Bai, bai: pues garie erekitzen tze... ¿cómo se le llama al mes de octubre o noviembre?

- Azaroa edo...

Pues azaroa izein tze, in tzire... últimos de octubre y primeros de noviembre, eztagit nola erraten den... uskeraz, lokarie, ta oloa ere bai. Ta gero zalkea? martxoan, edo... aprille, zalkea; ta...

- Eta erua?

Yerue? ori... a octubre ¿cómo se le llama? oktubre, izaten tzen oktubre. Y gero? a... eta gero bestze olo bat baze... bestze klase bat, t'ereitzen tze ori... aprilean edo ola, bertze olo bat, bertze...

- Bai, eta txitxirioa?

Txitxirioa? ori mayatzean.

- Eta, loratu, noiz egiten zen?

Zer? txitxirioa? a, pues, abuztuen, ya... agosto ¿cómo se llama? aguztu?

- Bai, abuztua.

Olako orduen, aguztuen ya... pasatuik kasi.

- Eta, bertzeak? garia eta oloa eta horiek? noiz ateratzen dira?

A, ori? pues... a! a julio ¿cómo se le llama?

- Ba, 'uztaila' erraten dugu guk.

Pues... orduen. Garie ta... oloa? ta... zalkea, ta bertzea, alolba, zer erraten dute? 'alholva', en castellano, eztait nola... ze izena duen, uskeraz. Oik denak, gariaren denboran: julio.

- Eta, zalkea eta erua?

Ori ere bai; denbora... garie ta zalkea ta erue? yerue? denbora...

- Kasik denbora berean?

Bai-bai-bai.

- Eta, gero, biltzeko, zer egin behar zen? horitu egin behar du, ezta? 'amarillear', ez?

Bai-bai, ongi amarilletuik ze, bai.

- 'Horitu' erraten zen?

Eztakit nola zaioten beño seguro, seguro ala izein tze. Ta, zalkea? eta erue eta dena, orituik edo, izen bear tzute, mozteko. Ta gero... garie mozten tze? ta... 
- Nola erraten da? 'mozten' edo 'ebakitzen'?

Ebakitzen.

- Ebakitzen hobeki, ezta?

Bai, bai; ebakitzen?... igiten, al cortar el trigo ‘igiten` le llamaban; si estaban cortando trigo... «Ze ai zete, ze ai zete emen?», «Emen, igiten».

- Bai, 'igitea' es 'la hoz'; hoceando, e?

Sí, sí; ta... erue ta zalkea ta ori? 'guadaña' nola erraten da, uskeraz?

- Handia? la guadaña... herri hauetan 'dalla' aditu dut.

Dalla, dalla, pues orrekin iten dire. Ta gero... orrekin moztu? te... gero, arrastelueki? oeki? paatu montone-, montoneo; emen monton bat? or bertze bat? or bertze bat? or bertze bat?... ta gero, emateko etxera? pues, sarde bateki? al carro ¿cómo se le llama?

- Karroa.

A! karrora! sarde batzueki? karrora; e... tzea, a la era ¿cómo se le llamaba?

- Larraina?

Larraña, larrañera.

- Eta, ez ziren egiten paxuak?

Bai, paxuek? ola... emen montton bat, or bertze bat, or bertze bat, or bertze bat? ta gero... garie paratzen tze... paxuetan. Sei edo zazpi montton oetaik? paxu ba-, paxuetan, sei ero zazpi?... ta fajo.

- Orduan, paxuak hartu, karroan sartu eta larrainera eraman...

Bai, ta larrañan paratzen tzire emen bat, or bertze bat, or bertze bat, or bertze bat? ta gero sarde bateki(n)? dena... arrotu? paatu...

- Bai, baina lehenago katxarro bat pasatzen zen hori guztia txikitzeko, ez?

Lenik paratzen tzire paxuek: emen bat, or bertze bat, or bertze bat, or bertze bat? ta... paxuek? pues lotuik, ordue(n)? ta, kendu lotue. Ta gero? sarde batekin? tenditu denna, larrañan.

- Barratu?

Barratu! ori, barratu; ta gero? pues, sartu azienda! ta bueltaka, bueltaka, bueltabueltaka?

- Eta, aziendak zer eramaten zuen gibeletik arrastaka?

Nola erraten tzioten? al trillo ¡cómo le llamaban?

- Estrazia?

Estrazian? sí, estrazie sería, estrazie, sí; aquello se les montaba a las caballerías, ta, idieri ere bai, ta denak bueltaka, bueltaka? ta... ordu erdi bet ero ola... ibilli, ola, bueltaka? ta... kendu azienda andik? ta, sarde batekin? buelta man, buelta emen, buelta man? ta berritz... idieki te... bueltaka, buelta, bueltakota? gero bertze buelta bat.

- Eta, estraziak zer egiten zuen? pikatu?

Piketu dena!

- Eta, azpian bazuen zerbait, ez? estraziak azpian zer zuen?

A! pues, sierra batzuk, eta... ortzak erraten tzioten; emen gantxo at, or bertze at, or bertze at, or bertze bat... arara, alde bateko ortz bat, ta aek e, ortz oen ondöan? sierra batzuk, sierra batzuk. Ta aek? ebakitzen tzue... garie aundiki.

- Zerezkoak ziren xerra haiek? burdinazkoak ala harrizkoak?

Lenao ere, arrizkoak e izein tzien beño nik enue zautu, ez-ez-ez, ez zautu. Nik zautu tutenak? burdiñezkoak, burdiñezkoak. 
- Eta, horren ondoan, zer bertze egiten zen? haizatu?

Gero, gañetik? pixket ola, aotza? kendu, garie... beitti... ondoan, geiltzen tze? ta gero, aotza kendu ola? ta kendu, ta gero? bildu monton batera? ta aizeratu. Ta gero, aizeratzen tzelaik? monton bat in? ta gero... zaku betzuk? zaku etzuk? zakuetan? tira!

- Alde batetik pikorra eta...

Beste aldea?... aotza.

- Eta, haizea ez zelarik?

Orduen... eje! kieto.

- Egon behar zen esperoan ea etortzen zen?

Bai-bai-bai-bai; ezpaze aizeik? an kieto.

- Baina, eultzia egiteko hautatuko zen haizea zebilen egun bat, ezta?

¿Qué, elegir el día del aire?

- Klaro.

Sí, pues gaur ezpaze aizea? pues bier, igual, iru o lau egun... an, garie gelditu, ta, egun artan? dena, iten ginue.

- Eta, haizerik ez bazen, ez zen egiten eultzia?

Bai-bai, eultzie bai, bai, eultzie bai. Gero, tortzen baze airia? aizia? pues torri, ezpazen tortzen? pues...

- Han gelditzen zen.

Bilduik, bilduik, ta... eskin batera apartatu? te... ta bertze egunian? bertze...

- Eta, bitartean, txoriak etorri eta jaten bazuten...

Bai, zerbait bai, zerbait beti, beño ez aunitz.

- Estraziaren gainean zerbait paratzen zen?

Estrazie gañean?

- Bai, fuerteago zapaltzeko?

Guk, gañan!

- Bai? mutil koxkorrak eta?

Bai-bai, ta... idiekin? bat gañan? ta bertze bat... altziniati, altzinian, idietako. Geo... ¿cómo se dice a las caballerías?

- Zaldiak, behorrak eta...

Bai, aek? kaguen! ¿cómo se dice, pa montar en el trillo?

- Gainera igan edo?

Gañera in? ta... arreatu... zaldiek o biorrak eoten tzen? ta, tira, a correr.

- Bai, pikorra aiseago puskatzeko...

Bai-bai-bai-bai, gañean.

- Aditu dut zenbait herritan paratzen zutela pinu bat hor, pisu gehiago edukitzeko.

A! ya... akaso, arri bet ero ola, arrie... bazuen pisu gutti? pues arri bet ero ola, arri bet o piñu et.

- Eta, larraina, eultzia egin aurretik, prestatu behar zen?

Bai, lenik? belarra moztu, zegatik ata-, atatzen tzen belarra, moztu; ta gero... iten tze? pues, 'muñige' erraten gindion: bein, beain kaka? monton batera? biltzen ginduen, ta gero arre-, arrek? bueno, larraña... arreglatzeko? pues bedezki amasatu... ure? ta botatzen ginduen larrañea, denetik. Ta gero, pino batekin? pino, kasko... duenik, batekin? idiekin?

- Kasko hori zer da? enborra? 'el tronco'? 
No, al contrario: de la rama, el casco de la rama. Arrekin? idiek, lotu? tä bueltaka, bueltaka, bueltaka ta bueltaka? geiltzen tze... kaguen! que se me olvidaba la era ¿cómo se llama?

- Larraina.

Larraña geiltzen tze? au bezala, dena, busti... ez, sekatzen tzelaik ure? gero ya, eultziak iteko, bai.

- Eta, usaintzen zuen? urrina botatzen zuen?

Ba! pixke bat bai, beño...

- 'Urrin' erraten da?

Bai, guk urrine erraten ginio, beño urrine botatzen tzue... lemiziko egunian, beño ya-ya, ya gero? sekatzen tzelaik? ez. Ola, ala iten tzen.

- Eta, ondoren, ahotza zakuetan sartu eta nora eramaten zen?

A, aotza? pues bakit e... al pajar ¿cómo se le llama?

- 'Ahoztegia' edo?

Auzte-, aoztegie, ta... granoa? itxean!

- Pikorra?

Bai, pikorra? pues, badire graneroak eta ola, an, etxean, kajon batzuk inik, ta an sartzen gindue. Emen garie, an zalkea, emen oloa ta ola, dena.

- Eta, gero, pikor hori ehotzeko... 'eho' edo 'iho' edo, nola erraten da 'moler'?

Iyo, iyo.

- Hori ehotzeko, nora eraman behar zen?

E! pues, ba-, bazire... al molino ¿cómo se le llama?

- 'Errota'?

Errotara maten ginduen!

- Non zegoen errota?

Non? an, Ezkiozko... Ezkioztik? Urdeitze; bai, badakizu etxe ori...

- A, bai, Urdaizko errota.

An, an berean.

- Hor bada ostatu ederra...

Bai, bai, bai, beño... bazute etxe zar bat, ugelde ondoan? ta an egiten tzute. Arara, arara ematen gindue, denek.

\section{Errotarekikoak (1987)}

- Zuk ikusi duzu nola ehotzen zen?

Bai, kusi ut, kusi ut beño eztait; sartzen tze ure? artzen tzute ure... ugeldetik; zenia ${ }^{20}$ erraten diote; baze? ta... patzen tze...

- Zenia?

'Zenia' erraten tzioten ure artzen tzuen... lekue; emen badago molinoa? ta, andik...

- Errota, bai; hor errota eta...

20 Arabieratik etorritako hitza da hau. Hona Iribarrenek (1984) dioena: CENIA. Aceña, canal de riego. [Zona Media]. // En el Fuero General aparece acenia y cenia en el sentido de aceña y molino. 
Bai, errota ta an, andik artzen tzute kanale bat? ugeldetik; tapatuik? te ola... iñik, pasar ta...

- Bide bat? ubide bat edo horrela?

Bai, ta faten tze... errotara. Ta andik? errotan? ud'arrekin? arri bet gaitze! ibiltzen tze bueltaka? ta, arrek? iten tzuen, dena molitu. Ni ez dait, nola deitzen tzen.

- 'Iyo' erran duzu lehen...

Io, iotu, bai, io, iotu, bai. Ta zak-, zakuera, paatzen tziren zakuk? an, leku beteik? len zakuek, kajon bat, batzueki, ta an ya ateratzen tze irine. Ta gero andik artu? te, zakuera? ta...

- Eta, 'molinero'-ari nola erraten zaio? errotaria?

Errotarie.

- Eta hark nola kobratzen zuen? dirutan edo irinaren partea?

Denetëk! nai duzu... dirue? ta... ezperen, andik artzen tzue. Ze ematen tzen erro-, errotrotara? andik artzen tzue; 'laka' erraten tzio orrei, orrei. Ta, na-, nabuzu pagatu dirue? igual.

- Eta, laka hori zenbat zen? ehuneko hamar edo?

Bai, eztait nik zenbat, beño... erregue, an erregue erraten gindue. Almute bat erreguen edo ola, eztakit nik ze, almötea da... eztakit nik, zenbat almute dien... erregue?

- Aber, badira erregua, erreguerdia, kuartala...

Ta... almutëa.

- Erreguak zenbat kilo ditu?

Pues gariek? ogeite bide.

- Hogeita bi kilo?

Bai; zalkëa? ogeite iru; erue? ogeite bide neski; ta... oloa? amasei, ta garagarra... ere amasei, kilo, erregue(k).

- Hori da gauza batzuk bertzeak baino astunagoak direlako, ez?

Bai-bai-bai-bai-bai.

- Neurria, kajona, beti berdina da...

Bai, neurria bai, neurria bai.

- Erran duzu ugaldetik errotara ura ekartzeko bazela... ze izena eman diozu?

Nik eztakit, euskeraz 'la cenia' le llamaban, euskeraz bai, en... (zuzenduz): vamos en... sí, en castellano 'la cenia', sí.

- Eta, hori zer da? bidea? el conducto?

Ez-ez, kondukto ez; in ola kanale bat? artu... presa badakizu zer den?

- Bai.

Pues, presa... presa bat in? ta gero, presa gañetik? pasten tzen... ure, sartzeko zeniara; ola... gauze bat? ta, ba! metro... metro at o... o gexao, ta bi metro edo ola de...

- Zabala?

Zabala, bai.

- Orduan, hori da bidea, ezta?

Bidea, bai, ta gero? errotatik pasten tze berriz ugeldera, ure, ure. Pastu errotatik? ta, berriz ugeldera.

- Eta, bazen ere urak mugitzen zuen errueda gaitz bat, ezta?

Bai-bai-bai-bai-bai.

- Eta, horrek ere bertze bat, ez? 
Bai.

- Honek ehotzen zuen...

Ta arrek eyotzen tzuen. Kasik e enüe... nola iten tzuen kasik, beño... arrieki beti ere iten tzuen, arri bet gaitze! ta arri ure?... zenbait, aunitz ibiltzen baze? paatzen tzen... p’al liso ¿cómo se llama?

- Leun edo.

Legun! ta legune paratzen tzelaik? piketu iten tzute, pixket, kaska-kaska-kaska, piketu? aspero... paratzeko.

- Latza, 'latza' erraten da?

Latza, bai.

- Eta, harri horiek badute bakoitzak bere izena?

Seguro, seguro oeti izein duela bere izena, bai.

- Bai, tresneria handia dago hor, makinaria hori ikusiko zenuen...

Bai, bai, bai, izein ddute, beño nik enaiz oroitzen nola diren.

- Ez zenuen kasu handirik egiten...

Ka! enue kasu egiten! ba, kasuek e-, aunitz aldiz egon nitze ni an, beño enaiz oroitzen.

- Eta, joaten zinen alde bakoitzean, zenbat zaku eramaten zenuen? edo karroarekin joaten zinen?

Zenbat aldiz kargakin beño, yago... beorraiki. Zaku pare bat: lau erregu, bortz erregu, bi zakuetan, paratu ongi...

- Eta, horiekin bazenuten ogia egiteko irina eta...

Ez, ogi iteko an etze eltzen, aziendendako bai, beño... ogi iteko etzuten or.

- Horra eramaten zenutena zen aziendarendako?

Bai, ogi iteko?... Larrasoañän; Larrasoaña badakizu non dagon!

- Bai, bai.

Pues an, baze 'Fábrica de Harinas' erraten tzioten; ogi iteko? andik.

- Eta, Urdaitzen, animaliendako?

Bai, bai, oloa eta garagarra sorik bai, oloa ta garagarra bai; txerriendako lo que es, dena... ola.

- Bai? dena ehorik?

Bai; ardiendako ez, ardiendako etze... batre iotzen, ardiendako eztä iotzen, beño... txerriei mateko? bai, dena.

- Eta, Larrasoañako errota igualtsua zen?

E! arrek bazue, makineri aundie bazue arrek, bai-ba. Distinto de eso...

- Hara ere joaten zineten?

Bai, arara? karroa-, karrueki; zazpi o zortzi o... amasatu o, nunbait artu? ta... an, iotzen tzuen? ta, gero... geratzen tzen? menudillo ta salbaö, separatzen tze... makina... fabrika bera? separatzen tzuen dena: salvao, harina, cáscara de trigo...

- Horiek zein izen dute euskaraz?

Uskeraz?... kaguensos! erderaz 'menudillo' erraten tzioten, kaskara oi.

- Zahia edo?

Zai, zaia bai. Zaiak? 'salvaö' erran nai zue, beño bi klase kentzen tzioten, garie-, gariei; iriñei, ona kentzeko? bi, bi klase're mi-, zaia? ta bertzea, 'menudillo' en... ¿en castellano? eztakit nola erraten tze en vasco. Ta oi denak? tzerriendako, gero...

- Menudillo hori?

Bai, tzerriendako. 


\section{Ibarreko eskolak non (1988)}

- Hara! traste hau gaizki paratua nuen; erranen duzu berriz?

Euskeraz?

- Bai, errain duzu?... 'Gure denboran, gure eskola-denboran'...

Gure eskola-denboran? faten gine... Zubirie eskolara, ta... Eskirozkoak? Ilerrazköak? Osterizkoak? Agorretaköak? Saigoskoak? Leranozköak? ta Usitxiköak; denak faten gine... Zubi(r)e, ta mintzeten gine... erderaz, beño Usitxikoak eta Leranozkoak? elkarrekin? beti... be! uskeraz, bertzekin ez, ezpaite, guk ez, tzakiren... no sé cómo decir.

- 'Ez ginakie' edo?

Ezpaikinakie guk... euskera? ta, gurekin elkar, gu beti erderaz, beño... elkardekin? aek, denak, beti euskeraz.

- Eta, bertzeekin ez, bertze herrietakoek ez zekitelako...

Ez, an... denak, erderaz.

- Eta, Larrasoaiñera zeintzuk joaten ziren? zein herritakoak?

Larrasoañera? Setöaingoak, Akerretakoak ta Inbuluzketakoak; eta... eztait ori. ori... Sarasibar eta... Idoi? oiek ere... Larrasoañera fain tzire seguro, eztakit seguro, beño nik uste Larrasoañera fain tzire.

- Eta, Akerreta eta...?

Akerreta? Larrasoañera!

- Eta Irure?

Irure ere bai, Larrasoañera, bai; Akerreta? Irure? Inbuluzketa? ta... Sarasibar eta Idoi? oiek? eztakit, nik uste Larrasoañera fain tziren oiek ere, eztakit seguro.

- Eta, Urdaitz nora faten zen?

Urdeitze? an berean, zute... eskola.

- Bai? herrian berean?

Bai; leena $(\mathrm{g})$ o? faten tzire Larrasoañera, beño gero in, in tzüte ${ }^{21} . .$. eskola an, errien? ta... errien berean... Ta gero, Setuaingoak ere faten tzire... Urdeitze gero, bai; lenbizik? Larrasoañera, ta gero? Urdäitze.

- Eta, Ilurdotz, Irotz, Zabaldika, Antxoritz eta hoiek?

Ilurdotz? errien berean; maten tziote eskola apezak, ta gero... bazen maixtrue, bai.

- Haiendako bakarrik?

Bai, bai.

- Eta, Beltzunegikoendako ere bai...

Bai, bai; ta gero, emen? beste erri oiek, eztagit! Irotzen nik uste, eon, punttela esko$\mathrm{la}^{22}$, ta Zabaldika ta... Antxoriz eta Irotza, torriko zire, eskolara, nik uste, eztait seguro ere, eztait seguro.

- Eta, Gendulain eta Zuriain eta...

Pues aek ere? ni eztakit nora fain tzire, or, eztagit nön, non iten tzen esköla. Zuriañen ezpaze sorik? eztakit, eztait seguro e, nola, nola... nora fain tzire(n).

- Eta, Tirapegikoak?

$21 \ddot{U}$ horren ahoskapena guztiz garbia da, ia-ia 'zite' aditzen uste dugu eta.

22 'Eskola puxka bat, eskola ttiki bat' edo, ote da hori? 
Larrasoañera.

- Eta, Ollokikoak?

Ollokikoak? pues oiek ere Irotza, fain tzire, Irotza? ero Uertera.

- Eta, Arletakoak? gauza bera, edo Irotza edo...

Irotza edo Uartera.

- Eta, Errea eta Zaikoak?

Erreak eta Zai... etzire faten iñora; apezak ematen tzioten... eskola, ta gero, maixtrue... izeten tzuten tenporera, bai.

- Han, Errean?

Errean, Errean, bai.

- Eta, Zaldaizkoak?

Oi, pues Zaldaizköak? e... Erreara fain tzire, bertze lekuten?... eztaizke fan, Erreara seguro, ezta gaizki.

- Eta, jada Arriasgoitin gaudelarik, horko Urrizelki, Zuntzarren, Zalba eta herrixka horietakoak non biltzen ziren badakizu?

Pues nik eztagit, Zuntzarrena seguro, ure ze errie printzipala, Zun(t)zarren; Urrizälki? Zun $(\mathrm{t})$ zarrena, seguro. Ta Galduroz eta oiek ere Zunzarrena fain tzire, nik uste! nik uste.

- Eta, hemengo, goitiko... Saigots erran duzu, baina Iragi, Urtasun eta Eugi? horiek nora?

Oiek... oiek? pues, Urtasun sorik e, Eugire fain tzire; ta Iragi? Iragi nik uste... an berian, izein tzute maëxtra tenporera, Iragin, bai.

- Eta, Eugikoak?

An berean, errian, errian bai.

- Herri handia da eta...

Bai, errian, an berian; ta Urtesungoak ere fain tzire Eugire, seguro. Zubirire eztire tortzen? etzire tortzen? da Eugire fain txire, aek... seguro.

\section{Izengoitiak direla-eta (1988)}

- Herrietako jendeak edo herriek berek badute moterik?

Bai! zenbaite pai.

- Badakizu bakarren bat edo? nola zaiote, nola erraten zaie herri bateko eta bertzekoei?

Usitxi... Usitxikoai? erraten ginioten 'baserri', baserri. Ta, gero? an, Leranotzen, baze gizon bat? erraten tzioten 'Ameka'; ta Larrastien (!) baze... bertzoat? erraten tzioten 'Diez'. Enaiz oroitzen yago, ba! izein tzire yago ere.

- Baina, nik ez dut erraten pertsonen moteak...

Erriek?

- Herrien moteak.

A! errien? pues Usitxikoai? baserri, ta... Ezkiozkoai eta... Ilarrazkoak ere? baserrik erraten tziote, bai, baserri.

- Eta, beste herrietakoei?

Pues nik eztakit, enaiz oroitzen, yao.

- 'Zabaldika madarika' eta...

Ez-ez, ez, ez; enaiz oroitzen. Zabaldika ta Irozko oiek nik eztakit aunitz zengatik, Eskirotzen bizi giñe gu? ta...

176 Fontes Linguae Vasconum (FLV), 125, enero-junio, 2018, 133-190

ISSN: 0046-435X ISSN-e: 2530-5832 
- Ez duzu aditu Erreakoei nola erraten zioten? edo Ilurdozkoei, edo moteren bat bazuten edo...

Erreakoak? ozt-, ozte, Ilordozkoak? 'txorgorri'.

- Nola?

Txolgorri, bai, txolgorri da, saten; ta Erreakoak? eztagit.

- Eta Zaikoak?

Zaikoak ere eztakit, nola deitzen.

- Irure eta Ezkirotz eta...

Eskirozkoai? ta Iregikuak? baserrik erraten tziote, oi... bai.

- Urdaizkoei?

Urdaizkoak? pues eztait, etzüte nik uste motea.

- Eta Inbuluzketa, Akerreta, Larrasoaña...

Larrasoaingoak?... bai, bazun zenbait ta, bai: billikak ${ }^{23}$. Bai, bai, ori, erri goi? aunitz urtez? zuten... sekretarioa ta, bere erriköa; ballean etzute... sartzen, aparte bizi izen tzire, 'pilla' erraten tziote orri, ta 'villicas', denok 'villicas'. 'Villicas' erraten tzioten Larrasoañai, 'villicas'.

- Eta, Zuriaingoek bazuten moterik? eta, Antxorizkoek?

Ez-ez, ezta-, nik eztakit, akaso bazuten, biño eztakit.

\section{OSTERITZ}

\subsection{Josefa Santesteban Lizoain}

\section{Zerri-hiltzea (1989)}

- Zerria hartu eta zer egiten zen?

Gero? bota an, gañera? ta, gero? meter el cuchillo, claro. Y así.

- Kanabita sartu?

Kanabite o, nola erran?...bai, klaro!

- Nondik sartzen da?

Nundik? lepotik, ja-ja!

- Eta, txerria ixilik egoten da? edo...

Bai! itxilik!

- Zer egiten du?

Ze iten du? pues chillar, claro.

- Oihu egin?

Oiu, oio, bai. No... no sé yo nada, no, poco entiendo, poco.

- Pixka bat bai...

$\mathrm{Ba}$ ! guti, gutti.

- Eta, gero, emazteki batek zer egiten zuen?

Ja! pues, odola artu, ta... klaro!

23 Gazt. 'villitas', alegia. 
- Eta, harekin zer egiten zuen?

Ze iten de-ten?

- Tripotak?

Ba! ez, tripota, jajajaja!...

- Eta, zer bertze egiten zuten? tzilintzatu?

Tzilintzatu? ta, ta gero, sekatu? ta... berritz, berritz, bertze aldera man, ta ala! aaa!... - Algo ya dice...

¡Poco! Yo, si habría seguido a lo mejor algo, pero el marido también, zegon más torpe...

\section{Ogi egiten (1989)}

- Ogia egin duzu?

Bai.

- Nola egiten zenuen?

Nola? pues... oratu o nola erraten da?

- Non oratzen zen? zeren gainean? nola erraten zitzaion mahai hari? oremahaia?

Oramaia, klaro!

- Eta, gero?

Gero... man... unos cortes? en... al de rematar, que se dice.

- Forma eman eta ebaki...

Bai, klaro!

- Eta, gero?

Ta gero sartu... neguan (!), dena, ori.

- Labean...

Labean; ta, ta gero...

- Nola sartzen ziren?

Con una pala.

- Eta, lehenbizi, garbitu behar zen labea?

Bai.

- Zerekin?

Pues, con... pues con una escoba, que solíamos hacer boje.

- Ezpel batekin?

Bai.

- Eta, berotu behar zen labea...

A! klaro! berotu? ta, gero sartu ogie? ta gero atra? ta ara man.

- Eta, labea berotzeko, zer egin behar zen? sua biztu?

A, klaro! sue bistu.

- Eta, nola ezagutzen zen ogia eginik zegoen?

Ah! claro... jse levantaba!

- Harrotu edo...

Bai, ta gero? (...)

- Eta, behin atera ondoan, zenbat egunetako zenuten?

Egunetako? zortzi eguntäko, bai, zu! zortzi eguntäko. Y más a gusto que, tan a gusto como ahora, el que se comía.

- Azken egunetarako gogorra egonen zen.

Ba! gogorra?... ola. 
- Pixka bat bai...

Pixko at, klaro!

- Baina, ongi jaten zen.

Bai, bai, bai, ongi.

- Eta, ez ziren egiten opil ttikiak edo?

Batzuk? ola, ta... igual, y otro? bollicos, que hacíamos, ¿chiquitos? aquellos que...

- Eta, bazen bertze bat, 'olata' zaikiona?

Olata bai.

- Eta, hori zertarako egiten zen?

Mateko... ori, apezai.

- Noiz hori, igandean? mezan edo?

Elizen, bai, elizen; tortzen tze... ta, bota. Ba! contento se llevaba, pa los perros y, juu!... sí-sí.

- Zakurrendako eramaten zituen?

Bai-bai... bai, ala, bai.

\section{Eultziaz zerbait (1989)}

- Eta, eultzia badakizu nola egiten zen?

Nola iten da? nola iten da?... ba, ors... past-, paratu... ori!

- Larraina?

Larraña, ta... ta gero? biorrekin o, biorrak beren etxean.

- Baina lehenik egin behar zen egitatu, ezta?

A! klaro, klaro.

- Eta, zerekin egiten zen? egitaiarekin?

Pues... 'la segadera' solíamos decir.

- Egitaia?

Bai, eeso! egitaia; usted mejor que (y)o sabe; ajaja!

- Zuk egitatu duzu?

Ez, ez, nik ez, nik ez.

- Eriak ez ebakitzeko erabiltzen ziren kazoletak? edo...

Bai.

- Edo zoketak edo... nola zaikioten?

No sé, ¿en vasco? zoketak.

- Eta, gero, egitatu, paxuak edo aurmenak egin, karrora eraman eta...?

Bai, bai.

- Baina, hori zuk erran behar duzu, ez nik...

No, ya le he dicho que no...

- Hala, un poquico más, que ya falta poco. Larrainean zer egiten zen, barratu?

Barratu? ta gero... buelta man? ta, ala! Ta gero? ori, biltzeko? como de escoba? jaa!

- Baina, barratu ondoan pasatzen zen gainetik gauza bat; nola zaikion? ¿'trillo'?

¡Trillo!

- Eta, euskaraz nola? estra-... estrazia?

Estrazie! bai, klaro.

- Nork tiratzen zuen estrazitik? nork eramaten, abereak?

Abreak. 
- Zein abere klasek?

Ili erra ${ }^{24}$.

- Eta, estraziak, orduan, zer egiten zuen?

Pues, ebaki.

- Pikorra ebaki... eta, ondoren, zer?

Pues no sé, no me acuerdo.

- Haizeak etorri behar zuen? jo behar zuen?

Bai! ola, gero «iHala, hala, hala! torri, torri!». Ya hemos estaö (...), gritando, que se deje...

- Eta, euskaraz nola? haizatu?

Aizeatu, klaro!

- Zerekin?

Sardea... klaro! y... primero con el sarde y después con la pala.

- Eta, haizatu ondoren, zer pasatzen zen?

Zer pasten tzen? iduritzen tzelaik... montonëa? gero pastu, ori, en la pasadera, pasar todo aquello.

- Pikorra alde batera eta...

Bai, ta gero? montonean, uzteunte.

- Pikorra ez zena, 'la paja'... nola zaio?

No sé.

- Ahotza?

Aotza, bai.

- Eta, hura nola biltzen zenuten edo zerekin?

Pues... doi ke maten tzen bertze aldera agotza? ta... lurrera? eso, grano.

- Ahotza, nora eramaten zen?

Nola? maindrean.

- Bai, baina nora, nora eramaten zen?

Nora? al pajar.

- Ahoztegira?

Bai, agozteie.

- Eta, pikorra?

Pikorra? etxera, klaro!

\section{ZAI}

\subsection{Celedonia Bizkai Santesteban}

\section{Hasierakoak (1989)}

- Zenbat urte dituzu?

Pues... lauetanogei? tt'amar. 
Eta, sortu, non sortu zinen?

Zaien; iru... anai-arreba. Lemixikoak? Zaien; beztxeak? Eskirotze, bai.

- Hiru anai-arreba izan zineten?

Iru, iru Zaien; bi... nesako? tta mutiko at, bai.

- Eta, gero, zenbat gehiago?

O! kero? bertze lau yago! ejeje!... zazpi, gine, zazpi.

- Eta, bertze horiek non erran duzu?

Eskirotzen.

- Eta, aitatamak nongoak ziren?

Etxe ontaköa ze ama, ta aitte? Larraingoakoa, ta zago zerbitzuen? Urdaitzen. Ta de ahí, asi ze... amaikin, eje! ta arrekin ttë, ezkondu ze.

- Zu sortu zinelarik, zenbat familia ziren Zaien?

Ooi!... pues, a lo mejor, lau edo bortz, izein txire; bat... lau sorik bai.

- Denbora hartan baziren lau etxe Zaien?

$\mathrm{Ni}$, bueno, denbora guti ere egon nitze, bai, ilbetea nada más. Eskirotza... torri giñe, ta or egon gine. Gero fan tzire Altzuzara, ta gero Aurretara... ahora [Iruñeko] kaputxinoetan daude.

\section{Otoitz-zati erdi ahantziak (1989)}

- Zuk, txikitan, ikasi zenuen euskaraz errezatzen?

Errezatzen ez.

- 'Aitagurea' eta horrela?

Bai, aitegurea?... a lo mejor me acordaré ahora: Aitte gurea, zeruetan zaudena... ejeje! - Santifika...

Xantifik-ka bedi, zure erreñue, kunpli bedi, zürë borondate sandua, zeruan bezala lurrean ere. Ejejeje!...

- Segi, segi...

Bai, eztaike... etzakit nola.

- 'Emaiguzu, eman ezaguzu'...

Gure egunorosko ogie...

- 'Barkatu'...

Barkatu dauzu, gure, guren zorrak, guk barkatzen dugun bezala... ejejeje! eztakit.

- 'Zor gaituztenei'?...

Santa Ma-, gero?

- 'Agur Maria'?

Agur Maria, zeruetan tzaudena, zeruen... bezala lurrean ere.

- Ez, 'Agur Maria graziaz betea, Jauna da zurekin'...

Bedeiketue da zure, andre guzien ertean ta bedeiketue da zure sabeleko frutue Jesus. Ejejeje!

- Eta, 'Santa Maria'?

Santa Maria, Jaungoikoaren ama, zuk otoi in tzazu gu bekatuarengatik, orai eta beti, gure eriotzeko orduan, Amen. Ejejejejeje!... Entonces íbamos a esamiñar, todos, al año una vez.

- Erran, erran ezazu euskaraz.

Y la que quiera (sic) hablaba de vasco y la que quería de castellano. Y así. 
- Eta, 'Kredoa' ikasi zenuen?

Ez, ez-ez.

- 'Sinestatzen dut' eta, hori ez?

Ez, ez-ez, ez; ta... Gurutze sanduaren? señaleagatik, gure etsaetatik, libre gaitxazu gure Jaune ta Jangoiko. Aitaren, Semearen, Jaunaren izenëan, Amen.

\section{Inauteriez zerbait (1989)}

Eje! bai uskeaz, eztakit! erriko nesako ateki? faten nitze... Urdeitze? te Illarratza te Eskirotza, te in tzute merendue... bide ere'do iru iten gintuen, bien, bien ertio, etxe... arren, abaiki? o guraiki, segun, erozeñeki(n). Zer bar kontatu, ejeje!... etzakit! eje!

- Ze ordutan ateratzen zineten?

Oi-oi!... goizëan, amarretan o amarka o ola, ejeje!... kasi etxe guzietaik.

- Eramaten zenuten zerbait? gerren bat edo?

Gerren bat? ta kapazo at, ejejeje!...

- Zertarako?

Pues kapazo artan, arrotzeak eta, ta ogie, ta kerreñean? txistorrak eta urdeiek, ejejeje!... tortille te it-, iten...

- 'Egiten genuen'?

Bai, tortilla.

- Eta, bazen mayordomorik edo horrelako zerbait?

Mayordomak eta... mayordomoak, bi klase, bi klasetaik: mayordomoa? ta mayordoma.

- Zer egiten zuten haiek?

Pues, ejeje! artsaldetan, erri kruxetan... bai, dantzatzen, bakarrik? mayordomoak. Ta, biek... dantza itten, ixten tzelaik? txokolatea... larrañera, kartzen gindiote, ure ta bolatue, ejeje!... da, dantzatu giñenak? eta... musikoak, artzen tzuten artaik; ejeje!

- Berandu arte ibiltzen ziren dantzan? hamarrak arte edo?

Beranduago; $a(t)$ saldean, ta ala fatean... ta arratsean egu-, maten tzuelaik, eguar$\operatorname{die}^{25}$ ? etxe(r)a; ejejeje!... Ezkiñen egoten orai bezala, kau guzien ${ }^{26} .$. ejejeje!...

- Musikariak nongoak ziren?

Be! aideak eta ola.

- Baina, nondik etortzen ziren?

Etxe guzietan izeten, itten tzire aidiak! musiköak eta... nesaköak? Gero, guresoak eta ola, Larraingoak eta ola etortzen tziren.

- Zein instrumentu jotzen ziren? akordeona eta gitarra? eta...

Gitarra? ta... artsaldetan, danborea eta txulubitta, tta denok, arra-, arratsetan? gitärra ta... bandurria.

- Ongi pasatzen zenuten, e?

Ongi, ongi, kontento... egoten nitzen, ejejeje!... ta, pastu ziren denbora aek! ejejeje!... perriz eztire itzuliko, ejeje!... 


\section{Iruñera oinez (1989)}

- Iruñera joan izan zara oinez? zangoz?

Bai-bai! bai. Ala-, aratakoa... faten nitzelaik? zangoz, eta gor, etxea... juaten giñelaik? orduen, abre gañän.

- Hara joateko zein herritatik pasatu behar da?

Ooi!... aunditz erriek!

- Oroitzen zara herrien izenez?

Irure, luego Larrasoaña, despues Zuriaiñe, gero Ugarte, gero Billaba, gero Iruñera.

- Eta, itzultzeko, etortzeko, abere gainean?

Bai-bai; Iruñen, abre gañera ta... Ugarten, artzen tzire... errekaituek, ai-... vaya.

- Errekaituek dira 'los recados', e?

Los encargos cogíamos en Ugarte y a la vuelta, otra vez montar, y hasta casa. Y así.

- Abere gainean hobeki, ez?

A! klaro.

\section{Festetan piperropilak (1989)}

- Hori ez duzu erran; hori noiz, inauterietan?

$\mathrm{Ez}$, festetan; amak eitten tzuen piperropillek eta, guk? bueno, (...), iten tzuen? ta gero maten gindion mutillei? ejeje! errikoai, tta aideak, segun.

- Aideak, 'los familiares', e?

Los familiares, claro.

- Eta, oroitzen zara nola egiten zituen amak piperropilak?

Oi-oi ama! enaiz e, orroitzen, jeje!...

- Zer behar da? irina, arrotzeak eta...

Eta txokolatea eta, ola, ejejeje!... haría la maseta un poco espesa, con la harina aquella...

- Lodi-lodia egiten zuen?

Ponía, bai, ejeje!... ejeje!...

\section{ERREA}

\subsection{Martin Esain Eugi}

\section{Errezitaturiko kantu-hondar batzuk $(1980)^{27}$}

«Donostiako zubipeko / sagararduan gotxoa / aren anet-, eraten ari nitzenean / autsi zakien lurreköa (!)». Eso le oí a un vasco, bueno, a un francés que estaba aquí, cargando, y ya me dijo que quería un culico. 
«Nere aita, zer dezkätzu? / enteratu te xoratu / enteratu ta xera, xera lotsatu / bizi modu on bat artu».

\section{Santa Feliciaren inguruko bertso-hondar desitxuratuak $(1980)^{28}$}

Se casaron, fuera de aquí, y le mandaron que no se casaría, con la francesa. Y al fin se casó y... y la llevó a Santa Clara. Y aquella vino con su caballo (...), montada en un caballo, a Santa Clara.

Y... «Zazpi errota battut, beren errenteki, aiek man biar dirazi, (...) utzi bizirik. Ezpada neregatik, nere barne (...)». Santa Clara estaba difunta (!), y... «Jetsi, jetsi, zaldi zuriti, nik, emen, il biar biaurkela, ortan etzan duderik». Y eso también, coño, muy bien solían cantar, mi abuela y después... mi padre. La tonada era muy bonita, sí, muy bonita. Y claro, le mataron. Pero... (Hurrengo aldi batez kontaera hein batean osatu zuen, geroxeago ikusiko denez).

\section{Elizako kantu baten zatia (1981)}

(Martinen alaba bat): ... ¿ ¿los versos de mayo?

Sí, pero el primero sé, los otros cuatro... «Egizezu Maria, gugatik erregu». ¿ł la tonada? también la, este Paco es el, el cuñaö del... ése sabe muy bien.

(Alaba): A ver, cante, cante... 'Egizu zuk'...

«... Maria, gugatik erregu, eriotzeko orduän, ez gaitzetzen galdu». (Gauza bera, geroxeago errepikatua): «Eitzu zu Maria, gugatik erregu, eriotzeko orduan, ez gaitzetzen galdu».

\section{Santa Feliciaren inguruko bertso-hondar desitxuratuak, bigarrenez (1981)}

- (Juanja $\left.{ }^{29}\right):$ ¿Se acuerda cuando estuvimos en Errea? habló de unas campanas que... Aquello era Santa Clara que era francesa. Sí, pero ese es muy largo... muy largo, y mi abuela y, cantaban ipero muy, muy bien!

- A ver, a ver si se acuerda...

Se fue un español a Francia y se enamoró de una, y ella también, y les dice que se iba a casar, y los padres que no, que no se casaría. Va y se viene a España, a presentarles a... al que se casó y, va y después le matan... a ella. Y eso está muy triste, y es una tonada muy bien también, pero, ijode! porque... y cuando vino, vino con el caballo blanco.

(Alaba): ¿Eso no es Santa Felicia?

¿E? que no, no era Santa Felicia, no, Santa Clara; Santa Felicia era la que vino aquí.

(Alaba): A Amokain...

28 'Santa Felicia' idatzi dugu guk, berriemailearen alabak, hurrengo urtean, aitak bertso-hondarren inguruko bertsio zabalxeagoa eman zuenean, iradoki zigun moduan. Eliza Katolikoak inoiz santutu ez arren tradizioak halako tratamendua eman dien Gillen eta Felicia anai-arreba akitaniarren ospea ezaguna da Eguesibarko Amokainen, Arangurengo Labion eta Obanos izeneko herrian, gutxienez, guk dakigula.

29 Martin jaunarengana hurbildu ginen bi aldietan -Errean aurrenik, 1980an, eta Iruñeko bere etxean, 1981ean-, Juan Javier Iturralde adiskide iruindarra izan genuen lagun eta partaide. 
A Amokain, bai. Y... y estaba encinta y, y le decía: «Zazpi errota baittut, beren errenteki, siete molinos tengo, todos sus obliganzas; todos los daré y, pa que me dejéis viva, y si no es por migo, por el que tengo dentro». ¡Claro! ¿pa qué le luce? y... «Jatsi, jatsi, zaldi zuriti, emen il biaurkela? ortan eztezu dudari».

Y le hace brincar del caballo, y después le, le mata su yerno, bueno, ¡su cuñaö, que tenía que ser! 'osaba' se dice en vasco, sí.

- Osaba 'tío' decimos, más bien.

Sí, tío, osaba en vasco. Y después, cuando le metió el cuchillo, la criatura dice que le... «Ai osaba, ai osaba, ori arma txorrotxa, orai okitzen diote nere amaren biotza».

- Sí, pero sabe más ¿no? lo del caballo blanco y...

Sí, ya sé, sí. Ella tenía un caballo, venía montada y, después le decían que no, que le tenían que matar y... y la otra pues, les decía pues, que ya les daría siete molinos que tenía y todas esas cosas, y después, al fin... (lehenxeago esanikoa errepikaturik): "Jatsi, jautsi, zaldi zuriti, bájate del caballo, que aquí has de morir, que aquí no hay duda... jautsi, jatsi».

«Klara: jausi, jautsi, zaldi zuriti, i, ik emen il beaukela? ortzan eztan duderi». Y le mataron. Pero es muy largo ese verso; nola da?

- Y, en euskara, ¿no se acuerda de nada más?

Sí, ya me acuerdo pero... y después, cuando le mataron a ella, las campanas de Atanazko ezkilak? beren burus yoka. Mira, las campanas que eran en Francia, en el pueblo que era, no sé cómo se llamaba seguro, Atanazko ezkila? otros dicen que otro nombre que tenía.

(Juanja): 'Atarratzeko' edo...

- 'Atarratzeko' igual; acaso sería de Tardets, aquí, cerca de Mauleón; Atarratzeko ezkilak?

Beren burus yoka. Cuando murió ella aquí, en España, cuando le mataron, pues las campanas empezaron allá, beren burus yoka? pues... sin tocar nadie.

- Beren buruz, de por sí...

Sí, sí, beren burus yoka. "Orduen partitzen tziote Santa Klarai biotza».

\subsection{Josefa Esain Eugi}

\section{Olaibarko Olaitzen adituriko kopla (1983)}

«Sukeldeti ganbarara / galdu nuen delantala». De la cocina al paso, que perdí el delantal. Y después ¿qué más?

- 'Kanta, kanta nik bezala'?

A!... «Kanta, kanta ni pezala / eztakienan i pezala / sukeldeti ganbarara / galdu nuen delantala». Y otra cosa no sé.

\section{San Juan bezperan, antza (1983)}

Y solía cantar, solía decir: «Sarna fuera, artoa Frantziera, garie Españara, kukusoak eta zorriek Franziera», los piejos y... y las pulgas a Francia. Ejeje!... y «garie Españera».

(Errepikapen zuzendua): «Sarna fuera, artoa Españara, Españera, kukusoak eta zorriek Frantziera ta garie Españera». El... trigo a España, eje!... Aquella también vasca cerrada era. Margarita se llamaba. 


\section{Zenbakiak, ehun arte nekez zenbatuak (1983)}

Eso también, ¿ya sabe?... bat, bide, iru, lau, borz, sei, zazpi, zortzi, bederatzi, amar, ameka, amabi, amiru, amalau, amabortz, amasei, amazazpi, emezortzi, emeretzi, ogei.

Ogeite bat, ogeite bide, ogeite iru, ogeite lau > ogeite sei, ogeite zazpi, ogeite zortzi, ogeite bederatzi, oeit'amar. Ogeit'ameka, oeit'amabi, oeit'amiru, ogeit'amalau > oeit'amasei, oeit'amazazpi, ogeit'emezortzi, ogeit'emeretzi, berrogei.

Berrogeite bat, berrogeite bide, berrogeite iru, berrogeite lau > berrogeite sei, berrogeite zazpi, berrogeite zortzi, berrogeite bederatzi > iruetanogei.

- (Zuzenduz): Berrogeita hamar...

Berrogeit'amar!...berrogeit'ameka,berrogeita....amabi,berrogeit'amiru,berrogeit'amalau $>$ berrogeit'amasei, berrogeit'amazazpi, berrogeit'emezortzi, berrogeit'hemeretzi > labetanogei; e?

- (Zuzenduz): Hiruetan hogei...

Iruetanogei, iruetanogeite bat, iruetanogeite bide, iruetanogeite iru, iruetanogeite lau > iruetanogeite sei, iruetanogeite zazpi, iruetanogeite zortzi, iruiten... bederatzi, iruetanogeit'amar. Iruetanogeita ameka, iruetanogeita... amabi? iruetanogeitä... (batzuk errepikatuko ditu): iruetanogeite sei, iruetanogeite zazpi, iruetanogeite zortzi...

- (Zuzenduz): Eta hemezortzi...

A! emezortzi? iruetei... t'emeretzi? berrogei!

- No.

¿Me hay confundido?

- Lauetan hogei, ¿sí? ¿cuánto es 'ochenta'?

Labetanogei, ochenta es labetanogei.

¿Y 'noventa'?

- Labetan-, labetanogeita amar.

¿Y 'cien'?

¿Cien? egun.

\subsection{Maria Etxeberria Erro ${ }^{30}$}

\section{Iruñeko Erruki-Etxera etorria (1987)}

- Zenbat denbora da Etxe honetan zaudela?

Nola? denbora, ze denbora? pues amar urte o... ameka ya.

- Eta, sortzez, nongoa zara zu?

Nungoa? ni naiz... sortu? Errean, Errean. Ta gero [gurasoak], pues fan tzire Inbuluzketara, ta artan ni...

- Han bizi zinen? Inbuluzketan?

30 Berriemaile honi bildu laginok ez ditugu behar bezain argi aditzen, horretan erabili genuen kasetea egoera onean ez bide zegoelako. Hori horrela, transkripzioak egitean zalantzak izan ditugu eta, ondorioz, tarte ilun batzuk ezkutatu ditugun moduan, akatsen bat edo beste ere, ziur, hortxe izango da. Herri honetan jasotzera iritsi ginen ekaiak urriak eta, jadanik agerian geratu bezala, desitxuratu samarrak daude; horixe izan zen, baina, aurkitu genuen zoritxarreko egoera. 
Bai-bai-bai; ta geo? klaro! il tzire denak, ya. Oi! batzuk, batzuk (...), ta atera ta atera ta, beño, pastu nuen?... -Jesús, María, a veces sale muy bien, y ahora nada- pastu nue... urte bat torri, torri gabe onara. Beño? torri, torri... naiz?

- 'Torri nitze' erran nahi duzu?

Sí, eta [arduradun] arrek ez nitza, nitza, niri... iten lekue. Bueno, ni ¿con toda la pena? pues, volvía, y otra vez venía, berriz torri nitze? ta, igual, eta (...); gero? artu... torri...

- 'Torri nitze'?

Ori? eta ai!... in tziden alkätu, ya, siempre diciendo que no, que no...

- Nola erran duzu, 'alketu'?

¡Ay, Jesús, María! alketu; alketzen nitze torritzera, tortzera.

- Que usted se avergonzaba de venir, que se apuraba, erran nahi duzu?

Sí, bai, eta... ba an, orei bezala? orai, torri... ibiltzen! eztut kotxeik ta daus! pa andar descansada. Y después...

- Eta, gero?

Ta gero? ta gero, pues... je! etor nitze? ola, eneatuik, hasta aquí. Otra vez me volvía; oi!... Dios mío, me dio apuro. Sí, pues siempre está diciendo que no...

- Eta alketzen zinen...

Bai, bai, eta bolbiti, bolbiti nitzen eguardien. Eta atsaldean? atsaldean, denak fan tzire bazkaltzera? ta atzo gelditu in gine batzuk... geldit $(\mathrm{t}) \mathrm{u}$ 're emen. Eta gizona? torri ze: «Ze ai zera emen?», neri. Pues, «Ez du bazkaldu biar?». «Eee! bai, bazkaldu in biaut, badaezpa egin dut». «E! zu in? be!». «iYa lo creo!». Sí, or nesaki bi? bañe dena kenduik! ddana! inte ola (...).

- Aizu, eta Erreako zure etxeak nola zuen izena?

Etxeberria.

- Etxeberria zure apellidoa da...

Bai-bai, Etxeberria, bai, ta Almeniz; Etxeberria? ama tu?... Erro Paxkal amak, eta ni? Etxeberria aitte? Etxeberria... Almeniz, Albeniz.

- Hortaz zu Etxeberria Erro zara.

Ama, ama?... a! bai, Etxeberri Erro, klaro!... Eta ala! beti pobre pero langille an, langille an, beño, etze... no era que produciría mucho, más que... pa vivir, pa vivir así, de una manera y denbora... bide au? gaixtoa, dena arrie ta... gaixtoa tzan ure, etze orai, orai bezala! An, andik, leiotik? etze, etze... karretera ta, pero, gero in tze, in tzute; beño bu! nere anaia ta... an bide, trabajar, trabajar... lanëan, lanëan, sí. Pero, no sé si ese era... Otxoa, el que hizo la carretera, el amo edo ola. Nausie, nausie... eta ola!

\section{Gazte-denborako egun arrunta (1987)}

Entonces, gure aitte, fan tze... ta badugu, pixket, pa trabajar.

- Alorra?

Alorrean, sí, alorrean. Ta in tzitu... goizik... goizik, levantar pronto, para ir un ratico a layar o azadear o lo que sea.

- Aita joaten zen?

Aita, fai (sic), ta utzi in biar dugu guk, ¡bien! etzue kasoik in. Eta ama? etxean, prestando... la comida o lo que sea. Y después...

- Eta, gero... 
Da gero? tortzen tze aite, eta fan tzire... con los animales. Bee eta... beak? ta, kanpora, atra tzun fin-fin... eun bet, Jesús, María! todo el día.

- Egun guztia?

Bai-bai, egun guzie, bai. Eta etorri ere, ber-, gero? pues, ya si era... primavera por ejemplo, pues...

- Primabera etortzen zelarik?

Tortzen tzelaik? ya... ze, ilun, ilune ya, ya el día más aburrido. Ya, gero? pues... beak ta, fan tzire bere etxera? denak? eta gero afaldu ta errosario rezatu, eta... ala! guti're zer! ba, guatzera! guatzea.

- Eta, errosarioa errezatu, erdaraz?

Sí-sí, sí. No sé, arpatiko zuten uskeraz? no.

\section{Ogigintzaz zerbait (1987)}

- Ogia egin duzu?

Ogie amak, amak.

- Ikusi zenuen nola egiten zuen? oroitzen zara?

Bai, oroitzen naiz, bai. Ta berueki, ederrak ogiek, orai beño obikiao, orai gaixtoak dire aunitz, gaizki, eztakit... eztugu, ¡no se puede partir! ori, pero antes...

- Ezin ebaki, e?

Bai, ez baki, bai-bai-bai; eta iduri u... ezin tzu ola? ta, ezin ebaki, bai. Pero cantes? lenao? eri (!) ederra ogie! uuu! ederra. Badugu... nola, ola erretzen tzie? ta gero pixket sobra... no sé cómo decir, ¿un montico? ¿un globico? alto.

- Eta, labea berotu behar zen?

Bai, berotzen bi... con bojes, orrea.

- Ezpela?

Ezpela, ezpela, sí, eta orrea? es muy, pero muy fuerte decían que era. ¿El boj? pues ya cogían la maña; «Mein tirezu gaek... batzuk, badakizu nola egin?» ta, sobra...

- Eta, horrekin ongi garbitzen zen?

Ongi, pero si sale malo el fuego, ekarri... se quemaba el pan. ¿Calentar? berotu te, aparte, ori, pa que no se afecte... ogie? bai. Ori oroitzen naiz ni. Pero ederra ogie! ooo!... orai emen guttiago.

- Eta, non paratzen zituen ogiak, labean sartzeko?

Non? beire, orai... andiago, andiago? dena; 'artesa', que se dice; un... cazolico blanco o no sé, con su taza. Y ella, entraba zerbait? y allí masaba, y masaba. Y después...

- Ez-ez, baina ogiak labean sartzeko...

A! ya-ya-ya; sartu... gure amak, sartzen tzuen? eta, dena junto, dena... ¿unido? eta...

- Dena batera, e?

Dena batera, dena batera, bai.

- Pala baten gainean edo?

Bai, bai, bai, pero obleak tapatu; tapatu zue... arpillera...

- Batekin?

Bai, eta, ongi.... ¿pa todo el día? ya egoin tzire.

- Egun guztiko...

Bai, eta se quedaba muy bien, muy bien... sí, sí. 


\section{BIBLIOGRAFIA}

Apat-Echebarne, A. [Irigarai, A.]. (1974). Una geografía diacrónica del euskara en Navarra. Iruñea: Diario de Navarra.

Aranzadi Zientzia Elkartea-Etnologia Mintegia. (1984 eta 1990). Euskalerriko Atlas Etnolinguistikoa (EAEL, I eta II). Donostia.

Artola, K. (2014). Ziorditik Uztarrozeraino, Nafarroan, euskararen hegoaldeko mugetan barrena, 1983an. Donostia: Aranzadi Zientzia Elkartea. (Munibe 34. gehigarria).

Artola, K. (2015). Erroibarko aldaeraren inguruan (1 - Ipar Erroibarko mintzairak). FLV , 120, 229-275.

Artola, K. (2016a). Erroibarko aldaeraren inguruan (2 - Hego Erroibarko azpialdaera. Lehen erdia). FLV, 121, 5-66.

Artola, K. (2016b). Erroibarko aldaeraren inguruan (3 - Hego Erroibarko azpialdaera. Bigarren erdia). FLV, 122, 245-301.

Artola, K. (2017a). Erroibarko aldaeraren inguruan (4 - Ipar Esteribarko azpialdaera). FLV , 123, 115-166.

Artola, K. (2017b). Erroibarko aldaeraren inguruan (5 - Esteribarko erdialdeko azpialdaera. Lehen erdia). FLV, 124, 299-354.

Azkue, R. M. de. (1969). Diccionario vasco-español-francés (repr. facsímil). Bilbo: La Gran Enciclopedia Vasca.

Bonaparte, L. L. 1863. Carte des sept provinces basques montrant la délimitation actuelle de l'euscara et sa division en dialectes, sous-dialectes et variétés. Londres: Stanford's Geographical Establishment.

Camino, I. (2003). Hego-Nafarreraren egituraz. FLV, 94, 427-468.

Camino, I. (2004) Hego-Nafarrera. Iruñea: Nafarroako Gobernua.

Campion, A. (1971) [1880]. Orreaga. Balada escrita en el dialecto guipuzcoano. Acompañada de versiones a los dialectos bizcaino, labortano y suletino y de diez y ocho variedades dialectales de la region bascongada de Nabarra desde Olazagutia hasta Roncal. Bilbo: La Gran Enciclopedia Vasca.

Echaide, A. M. (1989). El euskera en Navarra: Encuestas Lingüísticas (1965-1967). Donostia: Eusko Ikaskuntza.

Euskalerria Irratia. (1990). Nafarroako euskaldunen mintzoak, Iruñea: Nafarroako Gobernua.

Gaminde, I. (1985). Aditza Ipar Goi Nafarreraz. Iruñea: UEU.

Gaminde, I. (1986). Esteribarreko Aditzak. FLV, 48, 183-203.

Ibarra, O. (1995). Cispamplonés hizkeraren inguruan. ASJU, XXIX(1), 267-318.

Ibarra, O. (1996). Erroibarko lexikoaren gainean. Euskera, XLI(2. aldia), 929-973.

Ibarra, O. (1997). Erroko testu argitaragabe bat eta beste batzuen iruzkina. FLV, 75, 265-282.

Ibarra, O. (2000). Erroibarko eta Esteribarko hizkera. Iruñea: Nafarroako Unibertsitate Publikoa.

Ibarra, O. (2007). Erroibarko eta Esteribarko Hiztegia. Bilbo: Euskaltzaindia.

Intza'r, D. (1927). Esaera-zarrak. Euskera, VII(3-4), 4-16.

Intza'r, D. (1974). Naparroa-ko euskal-esaera zarrak. Iruñea: Diputación Foral de Navarra. 
Iribarren, J. M. (1984). Vocabulario navarro (nueva edición preparada y ampliada por Ricardo Ollaquindia). Iruñea: Príncipe de Viana Instituzioa.

Irigaray, J. (1979). Rescoldos del euskera en Iroz (valle de Esteribar, Navarra). FLV, 31, 163-169.

Pagola, R. M., Alkiza, E., Beola, A., Iribar, I. \& Iribar, J. J. (1996). Bonaparte ondareko eskuizkribuak-Hegoaldeko goi-nafarrera. Bilbo: Deustuko Unibertsitatea (Deiker)-Euskal Ikaskuntzen Institutua.

Pikabea, M. L. (1985). Expresiones temporales en el habla coloquial del valle de Erro. Euskera, $X X X(2$. aldia), 227-232.

Saragueta, P. (1979). Mezkiritz (Erroibar). CEEN, 31, 5-36.

Saragueta, P. (1982-3). Mezkirizko etxe barnea. AEF, 31, 31-48.

Saragueta, P. 1984, Mezkirizko langintza. AEF, 32, 115-134.

Satrustegi, J. M. (1987). Euskal testu zaharrak. Iruñea: Euskaltzaindia.

Yrizar, P. de. (1985). Aparición y desaparición de las formas verbales en -ako-, -eko-, en el alto-navarro meridional. In Aingeru Irigarayri Omenaldia (257-290. or.). Donostia: Eusko Ikaskuntza.

Yrizar, P. de. (1992). Morfología del verbo auxiliar alto navarro meridional. Iruñea: Euskaltzaindia. 